\title{
Analysis of the interaction between host factor Sam68 and viral elements during foot-and-mouth disease virus infections
}

\author{
Devendra K. Rai ${ }^{\dagger}$, Paul Lawrence ${ }^{\dagger}$, Anna Kloc, Elizabeth Schafer and Elizabeth Rieder ${ }^{*}$
}

\begin{abstract}
Background: The nuclear protein Src-associated protein of $68 \mathrm{kDa}$ in mitosis (Sam68) is known to bind RNA and be involved in cellular processes triggered in response to environmental stresses, including virus infection. Interestingly, Sam68 is a multi-functional protein implicated in the life cycle of retroviruses and picornaviruses and is also considered a marker of virus-induced stress granules (SGs). Recently, we demonstrated the partial redistribution of Sam68 to the cytoplasm in FMDV infected cells, its interaction with viral protease 3C $C^{\text {pro }}$, and found a significant reduction in viral titers as consequence of Sam68-specific siRNA knockdowns. Despite of that, details of how it benefits FMDV remains to be elucidated.
\end{abstract}

Methods: Sam68 cytoplasmic localization was examined by immunofluorescent microscopy, counterstaining with antibodies against Sam68, a viral capsid protein and markers of SGs. The relevance of RAAA motifs in the IRES was investigated using electromobility shift assays with Sam68 protein and parental and mutant FMDV RNAs. In addition, full genome WT and mutant or G-luc replicon RNAs were tested following transfection in mammalian cells. The impact of Sam68 depletion to virus protein and RNA synthesis was investigated in a cell-free system. Lastly, through co-immunoprecipitation, structural modeling, and subcellular fractionation, viral protein interactions with Sam68 were explored.

Results: FMDV-induced cytoplasmic redistribution of Sam68 resulted in it temporarily co-localizing with SG marker: TIA-1. Mutations that disrupted FMDV IRES RAAA motifs, with putative affinity to Sam68 in domain 3 and 4 cause a reduction on the formation of ribonucleoprotein complexes with this protein and resulted in non-viable progeny viruses and replication-impaired replicons. Furthermore, depletion of Sam68 in cell-free extracts greatly diminished FMDV RNA replication, which was restored by addition of recombinant Sam68. The results here demonstrated that Sam68 specifically co-precipitates with both FMDV $3 D^{\text {pol }}$ and $3 C^{\text {pro }}$ consistent with early observations of FMDV

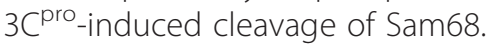

Conclusion: We have found that Sam68 is a specific binding partner for FMDV non-structural proteins $3 C^{\text {pro }}$ and $3 D^{\text {pol }}$ and showed that mutations at RAAA motifs in IRES domains 3 and 4 cause a decrease in Sam68 affinity to these RNA elements and rendered the mutant RNA non-viable. Interestingly, in FMDV infected cells re-localized Sam68 was transiently detected along with SG markers in the cytoplasm. These results support the importance of Sam68 as a host factor co-opted by FMDV during infection and demonstrate that Sam68 interact with both, FMDV RNA motifs in the IRES and viral non-structural proteins $3 C^{\text {pro }}$ and $3 D^{\text {pol }}$.

Keywords: Sam68, FMDV, 3C protease, 3D polymerase, IRES, Stress granules, RNA replication

\footnotetext{
* Correspondence: Elizabeth.Rieder@ars.usda.gov

${ }^{\dagger}$ Equal contributors

Foreign Animal Disease Research Unit, United States Department of

Agriculture, Agricultural Research Service, Plum Island Animal Disease Center,

USDA/ARS/NAA, P.O. Box 848, Greenport, NY 11944, USA
} 


\section{Background}

Foot-and-mouth disease virus (FMDV) is one of the most contagious animal viruses and causes disease in important livestock species including cattle, pigs, and sheep. The virus is represented by seven different serotypes: A, O, C, Asia1, SAT1, SAT2, and SAT3; each with a distinctive global distribution. Control of FMD outbreaks are typically combated through a combined strategy of mass vaccination and animal culling. Given the profound economic fallout following the spread of FMDV, it is of critical importance to understand the factors that influence FMDV virulence in order to design improved anti-viral strategies $[1,2]$.

FMDV is the prototypic member of the Aphthovirus genus of the Picornaviridae family. It possesses a singlestranded positive-sense RNA genome encoding a single polyprotein that is subsequently cleaved to produced four structural proteins (VP1, VP2, VP3, and VP4) and ten non-structural proteins $\left(\mathrm{L}^{\text {pro }}, 2 \mathrm{~A}, 2 \mathrm{~B}, 2 \mathrm{C}, 3 \mathrm{~A}, 3 \mathrm{~B}_{1,2,3}\right.$, $3 \mathrm{C}^{\mathrm{pro}}$, and $\left.3 \mathrm{D}^{\mathrm{pol}}\right)$. The genomic region coding for polyprotein is flanked by $5^{\prime}$ and $3^{\prime}$ non-translated regions (NTRs) [2, 3]. Highly structured internal ribosome entry site (IRES) elements in the 5 'NTR, allow the initiation of picornaviral polyprotein synthesis, while cap-mediated initiation is simultaneously repressed. IRES first described in picornaviruses [4-6], function via the recruitment of a number of canonical and non-canonical factors [6-10]. IRES are grouped into four types on the basis of their organization and interaction with translation factors and ribosomes. Many host proteins known as IRES transacting factors (ITAFs) also impact IRES activity. FMDV contains a type II IRES that is predicted to fold into five domains, followed by a polypyrimidine tract and by two alternative AUG initiation codons [11]. GNRA motif in domain 3 is critical to FMDV IRES activity, and mutations in its apical CAAA motif were found to influence IRES activity; however, the function of these two domains in relation to RNA-protein interaction activities awaits further elucidation [12].

In a previous study, we presented evidence suggesting that the $68 \mathrm{kDa}$ Src-associated protein in mitosis (Sam68) host protein binds to the IRES elements of FMDV, which could impact IRES translation activity. We had also shown appearance of Sam68 cleavage products in FMDV-infected cells and in the presence of semi-purified recombinant $3 \mathrm{C}$ proteinase $\left(3 \mathrm{C}^{\mathrm{pro}}\right)$. Interestingly, Sam68 knockdown resulted in a more significant reduction of FMDV titers than its impact in IRES-driven protein translation when using a bicistronic construct [13]. Apart from its role in FMDV infection, multiple reports have described Sam68 as an RNA-binding protein with a role in the replication of other picornaviruses [14-16] as well as retroviruses including the human immunodeficiency virus (HIV) [17-32]. Moreover, Sam68 has been found to be a multi-functional protein affecting a vast array of cellular functions, including RNAsplicing, tumorigenesis, cell cycle progression, apoptosis, adipogenesis, and signal transduction [33-47]. The diversity of functional roles of Sam68 appears to be partly regulated through various post-translational modifications including: tyrosine phosphorylation, serine/threonine phosphorylation, lysine acetylation, arginine methylation, and lysine sumoylation [37, 43, 48-53].

Here, we examined the partial re-localization of Sam68 from the nucleus to the cytoplasm in the context of two relevant host cell lines and provided evidence for Sam68 temporary co-localization with one constituent of stress granules (SGs): T-cell intracellular antigen 1 (TIA-1), in agreement with reports for Sam68 being a stress granule [54] marker for virus-induced cellular stress [16]. Moreover, we investigated the binding of Sam68 to the FMDV IRES, and assessed if UAAA sequence motifs are involved in complex formation. The significance of these interactions to the virus RNA replication was investigated through the depletion and restoration of Sam68 in a cell-free extract system. Consistent with its cleavage and contribution to viral RNA replication, Sam68 was found to co-localize and co-precipitate with FMDV $3 C^{\text {pro }}$ and $3 \mathrm{D}^{\mathrm{pol}}$, highlighting the importance of this host factor to the progression of FMDV infection.

\section{Results \\ Cytoplasmic Sam68 co-localizes with SG markers during FMDV infection}

In our previous study, FMDV infection was shown to induce a partial redistribution of the nuclear protein Sam68 to the cell cytoplasm in the LFBK cell line $[13,55,56]$. To confirm that this observation could be recapitulated in more widely distributed cell lines, immunofluorescent microscopy was performed using the recently described LFBK- $\alpha \mathrm{v} \beta 6$ and IBRS2 cell lines. As shown in Fig. 1, Sam68 is exclusively nuclear in mock-infected LFBK- $\alpha v \beta 6$ [55] and IBRS2 [57] cell lines. However, in the FMDV-infected cells (visualized by positive reactivity against the FMDV structural protein VP1) Sam68 exhibited partial redistribution to the cytoplasm, and this effect appeared more pronounced with the porcine IBRS2 cells.

Next we sought to determine if cytoplasmic Sam68 localized with specific SG markers as reported for poliovirus (PV) [16]. To test this possibility mock-infected or FMDV-infected cells were fixed at various time points post-infection and were evaluated by immunofluorescence microscopy (IFM) using antibodies specific to Sam68 as well as SG markers TIA-1 and Ras-GAP SH3 domain binding protein (G3BP) (Fig. 2). Both Sam68 and TIA-1 display diffuse nuclear fluorescence in mock infected (Fig. 2a) and at $1 \mathrm{~h}$ post infection (hpi) with FMDV (data not shown). At 3 hpi, both, cytoplasmic 


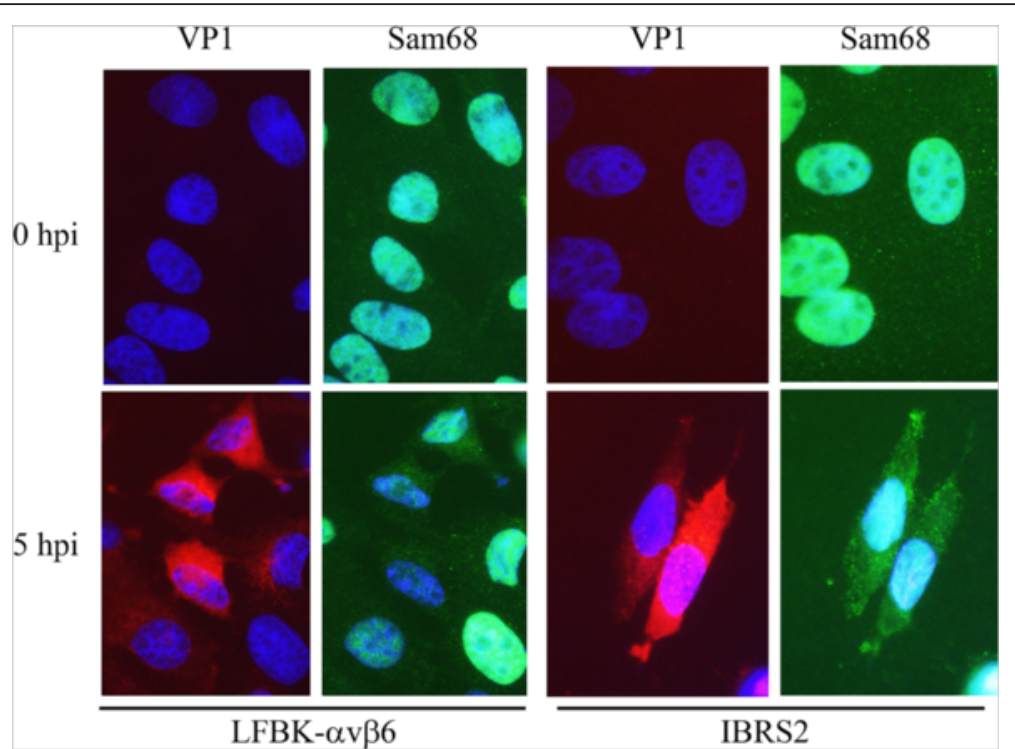

Fig. 1 Sam68 redistribution from the nucleus to the cytoplasm. Two different FMDV-susceptible cell lines (LFBK-avß6, left; and IBRS2, right) were mock-infected or infected with FMDV at a MOI of 10 and fixed at 5 hpi. Cells were examined by IFM probing with rabbit polyclonal anti-Sam68 followed by goat-anti-rabbit-AF488 (green) and mouse monoclonal anti-FMDV VP1 followed by goat-anti-mouse-AF568 (red). Nuclei were stained with DAPI (blue)

Sam68 and TIA-1 produced visible and overlapping fluorescent puncta in the cytoplasm. Interestingly, by 5 hpi, the specific fluorescent puncta have been replaced with diffuse cytoplasmic fluorescence. As shown in Fig. 2b, overlapping fluorescence can be observed for Sam68 and G3BP at $3 \mathrm{hpi}$, but unlike TIA-1, the G3BP cytoplasmic fluorescence is diffuse. However, by $5 \mathrm{hpi}$, punctate cytoplasmic G3BP specific fluorescence is observed, but not in co-localization with Sam68. Interestingly, it has been shown that different Picornaviruses can induce distinct SG compositions, where poliovirusinduced SGs contain Sam68 with G3BP and TIA-1 [16], but cardiovirus-induced SGs see polypyrimidine tract binding protein (PTB) in place of Sam68 [58]. Additionally, herpes simplex virus 2 (HSV-2) was shown to produce cytoplasmic SGs containing G3BP and poly-A binding protein (PABP), and a unique set of nuclear granules containing TIA-1 and Sam68 [59]. Therefore, virus-induced SGs are likely to be compositionally unique. The colocalization of Sam68 with TIA-1 in transient cytoplasmic granular structures in FMDV-infected cells resembles earlier observations in poliovirus and retroviruses $[16,17,32,60,61]$.

\section{Examination of Sam68-FMDV IRES complexes by electrophoretic mobility shift Assay and the requirement of Sam $68 \mathrm{KH}$ domain}

The initiation of cap-independent translation by IRES elements in the $5^{\prime}$ NTR of the picornavirus genome is regulated by RNA-RNA and RNA-protein interactions with canonical and non-canonical translation initiation factors $[8-10,12,62-66]$. Studies on the interaction between Sam68 and FMDV RNA elements indicated that Sam68 binds to IRES region [13]. To define the region within the FMDV IRES involved in this interaction we performed a pulldown experiment using recombinant Sam68 and biotinylated RNAs corresponding to different domains of the FMDV $\mathrm{A}_{24}$ IRES (predicted using $\mathrm{M}$-fold software). Figure $3 a$ displays a cartoon diagram of the FMDV IRES [see Background and References] [67, 68] showing the location of RAAA sequences in domain 3 and 4 that could potentially be involved in Sam68 binding. The panel below the cartoon diagram in Fig. 3a displays the pulldown results of Sam68-6H with either full-length IRES (labeled as 1-4) or domain 2, domain 2-4, and domain 4. As evident from the presence of Sam68 reactive bands, domains 4 and 2-4 combined appear to provide Sam68 binding specificity.

To further identify if the two UAAA motifs in domain 4 are involved in binding to Sam68, we prepared 5'-biotin labeled 65 nucleotide (nt) long RNA probes (spanning FMDV $\mathrm{A}_{24}$-Cru IRES nt 435-499) encoding the wild-type (WT) sequence or double mutated forms (UAAA to UACG), as described in Material and Methods and Table 1. The M-fold prediction indicated that both the WT and mutant probe maintain the unpaired nature of the two UAAA motifs as observed in the native FMDV IRES. The formation of ribonucleoprotein complex (RNP) between these synthetic RNA probes and Sam68-6H were examined by EMSA in the presence of a 100-fold excess of non-specific competitor tRNA (Fig. 3b). Slower migration of the probe visualized 


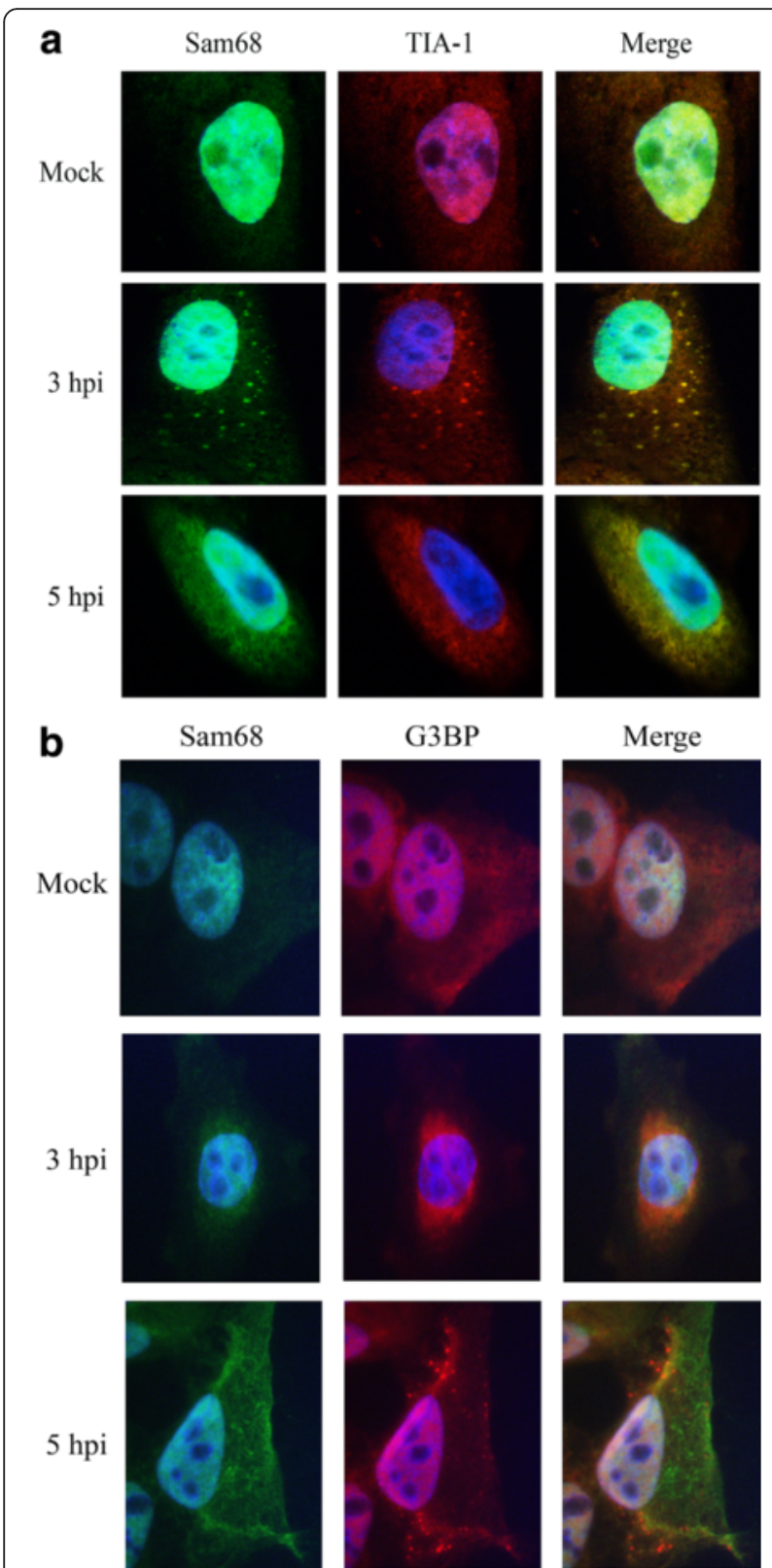

Fig. 2 FMDV-induced cytoplasmic Sam68 co-localizes with TIA-1. LFBK cells were mock-infected or infected with FMDV at a MOI of 10 and were fixed at 3 and 5 hpi. Cells were examined by IFM probing with rabbit polyclonal anti-Sam68 followed by goat-anti-rabbit-AF488 (green) and goat polyclonal anti-TIA-1 (a) or mouse monoclonal anti-G3BP (b) followed by donkey-anti-goat-AF568 (red, a) or goat-antimouse-AF568 (red; b). Nuclei were stained with DAPI (blue)

by RNP complex formed in Sam68 and WT domain 4 probe mixtures (Fig. 3b, left panel) was detected in a dose-dependent manner with $50 \%$ binding $\left(\mathrm{Kd}_{50}\right)$ in the range of $2-5 \mu \mathrm{M}$, under the experimental conditions. Interestingly, although the mutant domain 4 probe also produced RNP in the presence of Sam68, this binding required approximately 10 -fold higher amounts of the protein to produce the same amount of RNP products as with the WT domain 4 probe (Fig. $3 \mathrm{~b}$, right panel). Therefore, under the experimental conditions, it appears that the double UACG mutation diminishes Sam68 binding to domain 4 RNA. We believe that the widespread RNP bands observed in EMSA could be due to more than one oligomer form of Sam68 [69].

To further validate the specific binding between Sam68 and IRES, a mutant Sam68 lacking the KH RNAbinding domain (Sam68-KH-del) was expressed and tested side-by-side with full-length protein in an EMSA assay. To this end, EMSA experiments were carried out using WT domain 4 probe (as described above) and either an intact (Sam68-WT) or mutant Sam68 (Sam68KH-del), (Fig. 3c, upper panel). The EMSA results in the lower panel of Fig. 3c show that the Sam68-WT but not the Sam68-KH-del protein is capable of forming RNP with domain 4 RNA probe.

Having determined a specific interaction between Sam68 and UAAA containing RNA molecule, we next examined if other IRES domains could interfere with the formation of Sam68-domain 4 RNPs. As shown in Fig. 3d, gel shift experiments were carried out using 5' biotin labeled WT domain 4 probes-Sam68 mixtures either alone (lane 1) or combined with unlabeled transcript RNAs corresponding to: full-length IRES (lane 3), cis-acting replication element (cre, lane 4), the Sfragment (lane 5), IRES domain 2 (lane 6), IRES domain 3 (lane 7), and IRES domain 4 (lane 8) in 10-fold molar excess relative to the probe. Lane 9 contains probe only and lane 2 was left blank. Consistent with earlier observations (Fig. 3a and [13]), the cre (lane 4), S-fragment (lane 5), and IRES domain 2 (lane 6) did not effectively compete with Sam68-domain 4 RNP. For reasons not fully understood, some disruption on RNP signal was detected with the cre, S-fragment, and domain 2 under the current experimental conditions. Nonetheless, IRES domain 3 and 4 that contain the RAAA motif fully disrupted the Sam68-domain 4 RNP complexes, highlighting a major involvement of these IRES elements in RNP formation. As expected, unlabeled full-length IRES (containing domains 1-4) in 10-fold molar excess to the probe also effectively displaced the Sam68-domain 4 RNP complexes.

\section{Effect of Sam68-depletion on FMDV protein and RNA synthesis using cell-free extracts}

In our previous study, we observed that Sam68 knockdown by siRNA led to a significant reduction in virus titers. Intriguingly, the negative impact of this knockdown on virus yields was more pronounced than on the levels of FMDV IRES-driven translation measured with a bicistronic construct [13]. Based on these observations and the results described above, we were compelled to examine the role of 


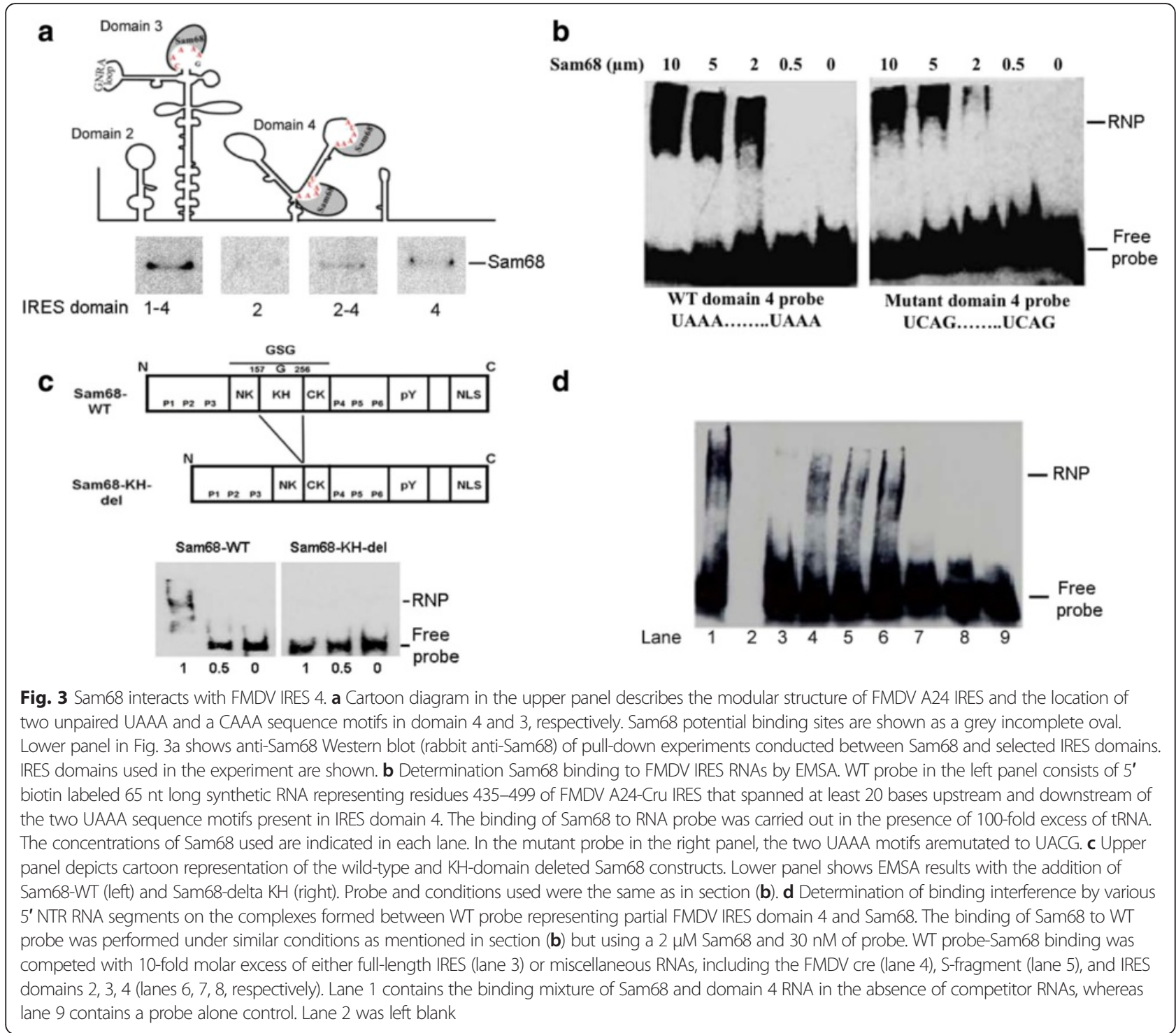

Sam68 during FMDV infection in more detail. To this end, we programmed BHK-21 cell-free extracts (CFE) with FMDV RNA to measure protein and RNA synthesis. As shown in Fig. 4, the experiments were conducted using CFE where Sam68 was depleted (using anti-Sam68 antibody) or tested following the addition of Sam68-6H. The Western blot in Fig. 4a shows the depletion of Sam68 in CFE treated with anti-Sam68 antibody directed against the $\mathrm{N}$-terminus of Sam68. In Fig. 4b, 500 ng of transcript FMDV RNA was used to program CFE reactions in Sam68-depleted $(0 \mu \mathrm{M})$ or supplemented with $1 \mu \mathrm{M}$ Sam68-6H. Under these conditions, viral protein synthesis (measured by the expression of $3 \mathrm{D}^{\mathrm{pol}}$ ) showed no differences between reactions programed with non-depleted, depleted (only) and depleted CFE supplemented with $1 \mu \mathrm{M}$ Sam68-6H (Fig. 4b). However, we were not able to conclude that the depletion of Sam68 is non-deleterious to viral translation because it could also be argued that other Sam68 splice variants lacking the Sam68 N-terminus were not eliminated in the depleted extracts due to the fact that an N-terminal antibody was used (see Additional file 1: Figure S1). Indeed, there are reports describing Sam68-like molecules, SLM-1 and SLM-2, which have an intact KHdomain but lack the Sam68 N-terminus, may function in binding to the FMDV IRES [70, 71]. A sequence alignment of Sam68 and SLMs shown in Additional file 1: Figure S1 describes the differences between SLMs and full-length Sam68 protein.

Moreover, performing the assay under more stringent conditions, such as lowering the RNA concentrations and/ or shortening the incubations times may reveal subtle differences in translation between mutant and parental RNAs. In contrast, in the Sam68-depleted extract a consistent reduction in FMDV RNA synthesis was measured (Fig. 4c). 
Table 1 Oligonucleotides used in this study

\begin{tabular}{|c|c|}
\hline Primer Name & Sequence \\
\hline P-Q180AForward Sam68 & GGGGAAGATTCTTGGACCAGCCGGGAATACAATCAAAAGAC \\
\hline P-Q180A-Reverse Sam68 & GTCTITTATTGTATTCCCGGCTGGTCCAAGAATCTTCCCC \\
\hline P-Q391A-Forward Sam68 & GAAGGCTATTACAGCCAGAGTGCCGGGGACTCAGAATATTATGAC \\
\hline P-Q391A-Reverse Sam68 & GTCATAATATTCTGAGTCCCCGGCACTCTGGCTGTAATAGCCTTC \\
\hline P1579 S IRES -T7 & GGATAATACGACTCACTATAGGTITICATGAGAAATGGGACGTCTG \\
\hline P1580 AS IRES & CCTTCCTGTGGCTCGTGGTAGG \\
\hline P1329 S A24-T7cre & GGATAATACGACTCACTATAGGGCTTGAGGAGGACTTG \\
\hline P1330 AS A 24 -cre & GTCAGTTGGGGAAACCTGCTT \\
\hline P-21036-IRES loop 1-T7 & GATAATACGACTCACTATAGGTITCATGAGAAATGGG \\
\hline P-21037-IRES loop 1 Rev & CTGCTTAGATCGTG \\
\hline P-1584-IRES loop 2 For-T7 & GATAATACGACTCACTATAGGCAAACCGTGCAATTTG \\
\hline P-1585-IRES loop 2 Rev & GTACAAAGTGTCACCCCTCTAGACCTGG \\
\hline P-21034-IRES loop 3 For -T7 & GGATAATACGACTCACTATAGGGTGTTTGACTCCACGTTCG \\
\hline P-21035-IRES loop 3 Rev & GCCTGTCACCAGTGCTTGAGTACCAG \\
\hline P-1581-IRES-4 For -T7 & GGATAATACGACTCACTATAGGGACAGGCTAAGGATGCCCTT \\
\hline P-1582-IRES-4 Rev & ATTCAGACATAGAAGCTIITTAAACCGGGCG \\
\hline WT domain 4 probe & 5'Biotin-AAGGGGACCGGGGCUUCUAUAAAAGCGCCCGGUUUAAAAAGCUUCUAUGUCUGAAUAGGUGACCG-3' \\
\hline Mut domain 4 probe & 5'Biotin-AAGGGGACCGGGGCUUCUAUACGAGCGCCCGGUUUACGAAGCUUCUAUGUCUGAAUAGGUGACCG-3' \\
\hline P-2182-Infusion-FMDV $A_{24}$ ires For & GCTITCCAGGTCTAGAGGGGTGACACTTTGTACTG \\
\hline P-2183-Infusion-FMDVa 24 ires Rev & GGTTGTTGGGTCTAGAATAGAACACTTTTCTCTCACC \\
\hline
\end{tabular}

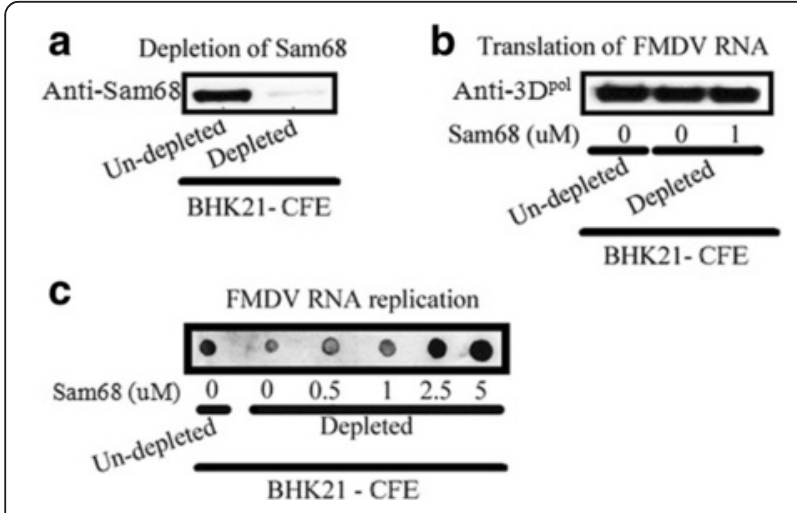

Fig. 4 Effect of Sam68-depletion on FMDV protein and RNA synthesis using cell-free extracts. a Depletion of Sam68 from BHK-21 CFE. BHK-21 CFE was prepared as described in Materials and Methods. The depletion of Sam68 was confirmed by Western blot probing of non-depleted (left lane) and depleted (right lane) extract with anti-Sam68. $\mathbf{b}$ Determination of the effect of Sam68-6H addition on the translation of FMDV $\mathrm{A}_{24}$-Cru. FMDV $\mathrm{A}_{24}$-Cru RNA was translated using non-depleted or depleted BHK-21 CFE that were supplemented with 0 or $1 \mu \mathrm{M}$ Sam68-6H as marked. The reaction was carried out at $32^{\circ} \mathrm{C}$ for $2 \mathrm{~h}$ and the products were resolved by SDS-PAGE and Western blot probed for FMDV $3 D^{\text {pol }}$. c Determination of the effect of Sam68-6H addition on the synthesis of FMDV $\mathrm{A}_{24}-\mathrm{Cru}$ RNA. FMDV $A_{24}$-Cru RNA was used for RNA synthesis using non-depleted or depleted BHK-21 CFE that were supplemented with 0-2.5 $\mu \mathrm{M}$ Sam68-6H as marked. The reaction was carried out at $37^{\circ} \mathrm{C}$ for $5 \mathrm{~h}$ and the products were SDS-PAGE resolved by dot blotting
Moreover, addition of Sam68-6H to the depleted CFE displayed a dose-dependent ( 0.5 to $5 \mu \mathrm{M})$ stimulation, evident with increased signal in the dot-blot shown in Fig. 4c. These results provide evidence to suggest a potential involvement of Sam68 host protein in the stimulation of FMDV replication.

\section{Examination of domain 3 and 4 IRES mutations using FMDV full-length cDNA clones and $A_{24}$ G-luc replicons} To understand the functional significance of Sam68binding to the FMDV IRES, we next examined the effect of a CAAA to CACG mutation in domain 3 and on two UAAA to UACG mutations in domain 4 using FMDV $\mathrm{A}_{24} \mathrm{Cru}$ infectious cDNA clone and G-luciferase (G-luc) FMDV replicons. The full genome WT or I3 (CAAA to CACG), I4 (two UAAA to UACG), or the two combined (I34) mutant plasmids were first linearized by SwaI restriction enzyme digestion and then transcribed into RNA, and electroporated into BHK-21 cells. Twenty-four hours later, the transfected cells were freeze-thawed, and a fraction of the lysate $\left(1 / 10^{\text {th }}\right)$ was used to initiate next passage. In contrast to the WT virus that exhibited visible cytopathic effect in the second passage in BHK-21 cells, no viable virus was recovered from any of the mutant RNAs even after 7 blind passages (data not shown). This was a surprising observation that led to suspicions about the ability of the mutant RNAs to translate and/or replicate. The same panel of IRES 
mutations were inserted into FMDV $\mathrm{A}_{24}$ G-luc replicons (Fig. 5) to evaluate the importance of these sequence motifs on genome replication and translation. In the G-luc replicon plasmids, the FMDV leader and capsid coding sequences were replaced by gaussia luciferase reporter gene (G-luc, see Methods). Plasmids encoding WT FMDV $\mathrm{A}_{24}$ replicon $\left(\mathrm{pA}_{24} \mathrm{G}\right.$-luc) or mutant $\left(\mathrm{pA}_{24} \mathrm{I} 3 \mathrm{G}\right.$-luc, $\mathrm{pA}_{24} \mathrm{I} 4 \mathrm{G}$ luc and $\mathrm{pA}_{24} \mathrm{I} 34$ G-luc) sequences, were digested with SwaI restriction enzyme prior to the RNA transcription. The RNA were then transfected into BHK-21 cells and samples were collected at $0,2,6$ and $24 \mathrm{~h}$ post transfection (hpt) and examined for G-luc expression. As shown in Fig. 5a, the G-luc activity for mutant replicons RNAs was substantially reduced at all time points compared to the WT replicon. At $24 \mathrm{hpt}$, the G-luc activity for all mutant replicons was less than $5 \%$ of that measured for the WT G-luc. In Fig. 5b, G-luc activity was examined using truncated replicon RNAs obtained by digestion of the $\mathrm{pA}_{24} \mathrm{G}$-luc plasmids using $\mathrm{M} f e \mathrm{I}$ restriction digests (Fig. 5b, upper panel cartoon). These (G-luc-P2) truncated constructs are lacking $3 \mathrm{D}^{\text {pol }}$, allowing for measurements of the translation of the input RNA driven by FMDV IRES (WT or mutant). The results in Fig. 5b show that G-luc activity was significantly reduced for mutant (I3, I4, and I34) G-luc replicons compared to WT G-luc RNA, consistent with inhibition of replication observed in Fig. 5a. Together, these results suggest that FMDV IRES function is dependent of the integrity of the RAAA motifs in both domain 3 and 4 .

\section{Sam68 interacts with FMDV $3 C^{\text {pro }}$ and $3 D^{\text {pol }}$ non-structural proteins}

Based on the observations related to Sam68 impact on FMDV RNA replication, we carried out experiments to investigate if Sam68 physically interacts with the FMDV RNA-dependent RNA polymerase $3 D^{\text {pol }}$ as had previously been shown for poliovirus [14]. To that end, we performed the following experiments: (i) coimmunoprecipitation combined with Western blot analysis in FMDV-infected cells, (ii) indirect enzyme-linked immunosorbent assay (ELISA) performed on Sam68 coated plates using $3 \mathrm{D}^{\mathrm{pol}}$ peptides binders, and (iii) structural prediction and molecular docking of Sam68 and FMDV 3D $\mathrm{D}^{\mathrm{pol}}$ (Fig. 6).

For the co-immunoprecipitation analysis, BHK-21 cells were either mock infected or infected with FMDV at a MOI of 10 (Fig. 6a). Five hours post-infection, cells were lysed and the lysates were immunoprecipitated [72] with either anti-FMDV $3 \mathrm{D}^{\text {pol }}$ or anti-Sam68 (N-terminal antibody) crosslinked to protein G Dynabeads. As a control, lysates of virus-infected cells were subject to IP with an isotype antibody control crosslinked to protein $\mathrm{G}$ as described above. The left panel of Fig. 6a shows the Western blot of the FMDV $3 \mathrm{D}^{\mathrm{pol}}$ IP developed with anti-Sam68. In lane 1, a control IP with isotypic antibody shows the absence of a Sam68 specific band. The two faint bands of approximately 20 and $30 \mathrm{kDa}$ are non-specific proteins pulled down by this antibody. Lanes 2 and 3 are the control cell lysates at 1:10 dilution from mock-infected and FMDV-infected cell lysates, respectively. As expected, the endogenous Sam68 as well as the previously described $55 \mathrm{kDa}$ Sam68-like-mammalian protein 2 (SLM-2) $[13,73]$ were visualized in both control lanes. Lane 4 shows that anti-3D ${ }^{\text {pol }}$ IP pulled down Sam68 specific protein band of $68 \mathrm{kDa}$ and three additional Sam68 reactive bands. In addition to the proteins of expected size in the IP experiments, higher molecular weight Sam68 reactive bands in FMDV 3D ${ }^{\text {pol }}$ IP could be attributed to a shift due post-translational modifications
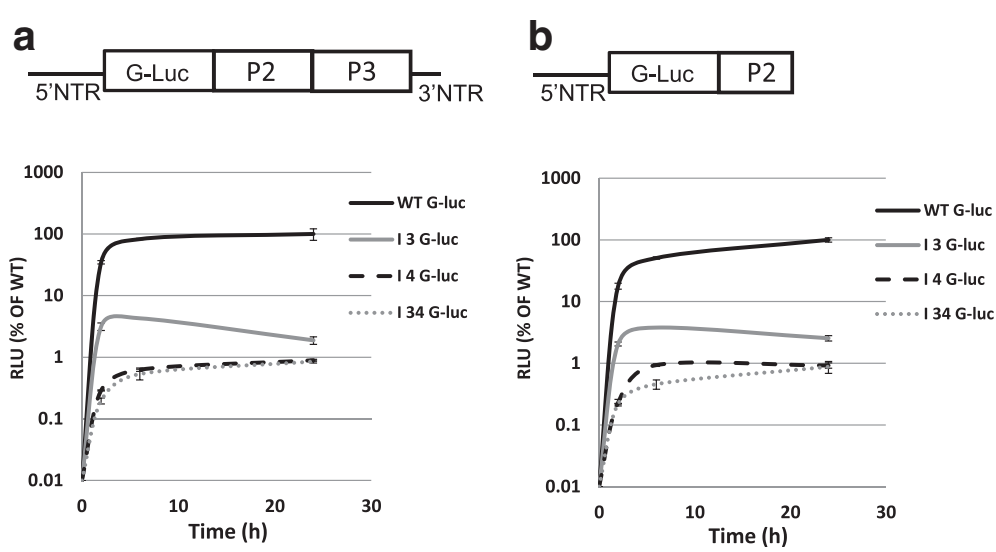

Fig. 5 Replication and translation kinetics of WT G-luc, I 3 G-luc, I 4 G-luc and I 34 G-luc replicon constructs. a Schematic representation of the G-luc replicon construct digested with Swal restriction enzyme (above). The luciferase activity of transcript RNAs for WT G-luc, I 3 G-luc, I 4 G-luc and I 34 G-luc Swal digested replicon plasmids. On the Y-axis, G-luc signals are expressed in relative luciferase units (RLU) per nanogram of protein and the error bars represent the standard deviation from two independent experiments. X-axis values indicate the time points of G-luc measurement (hours post-transfection). WT, I 3, I 4 and I 34 G-luc are marked as solid black, solid gray, dotted gray and point gray lines, respectively. b Schematic representation of truncated G-luc replicon produced by digestion with Mfel restriction enzyme (above) 


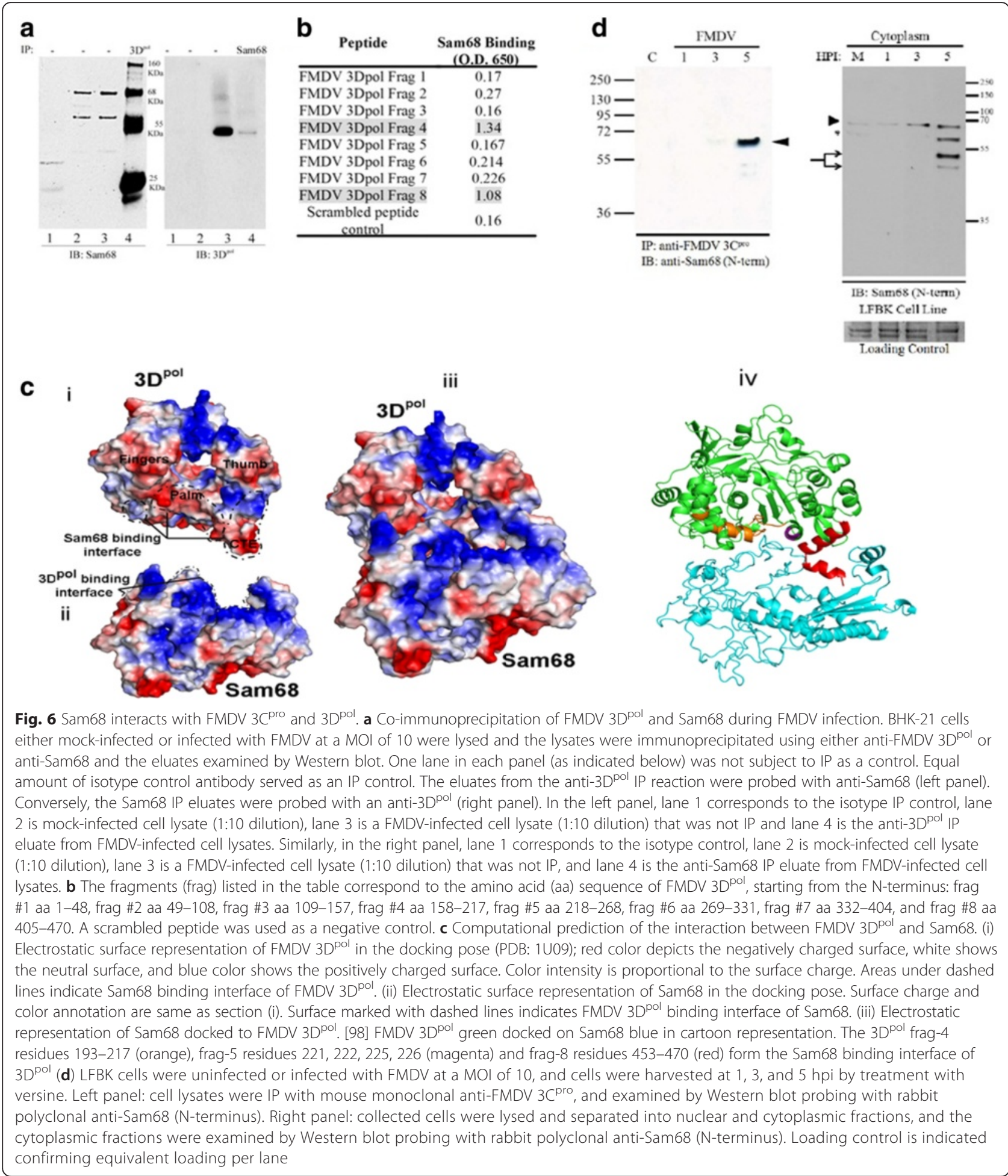

of Sam68 [69]. The lower molecular weight bands of $\sim 55$ and $\sim 25 \mathrm{kDa}$ have been also reported by Lawrence et al., and discussed therein [13]. Alternatively, the known adaptor function of Sam68 that bridges two or more proteins of importance in cell signaling $[72,74]$ may contribute to the binding of $3 \mathrm{D}^{\mathrm{pol}}$ and other cellular proteins to
Sam68 thus producing the higher molecular weight protein bands. The right panel of Fig. 6a corresponds to results of an anti-Sam68 IP and the corresponding controls examined by Western blot for the presence of FMDV $3 \mathrm{D}^{\mathrm{pol}}$. The isotype antibody IP (lane 1) and mock-infected cell lysates (lane 2) showed no 3D ${ }^{\text {pol }}$ specific band. In 
contrast, lane 3 (FMDV-infected cell lysates control) and lane 4 (anti-Sam68 IP) showed 3D ${ }^{\text {pol }}$ specific bands. Together, the reciprocal pulldown experiments of Sam68 and FMDV $3 D^{\text {pol }}$ from FMDV-infected cell lysates provides the evidence for Sam68 and FMDV $3 \mathrm{D}^{\mathrm{pol}}$ interaction in virus-infected cells.

In an effort to determine the region of $3 \mathrm{D}^{\text {pol }}$ that interacts with Sam68, we probed for binding of Sam68 in an ELISA using a 3D peptide fragment library consisting of fragments of about 50 amino acids (aa) in length starting from the N-terminus of $3 \mathrm{D}^{\mathrm{pol}}$ (frag-1: aa 1-48, frag-2: aa 49-108, frag-3: aa 109-157, frag-4: aa 158-217, frag-5: aa 218-268, frag-6: aa 269-331, frag-7: aa 332-404, frag-8: aa 405-470). As evident from the data, frag-4 and frag- 8 of $3 D^{\text {pol }}$ bind to Sam68 with high affinity whereas frag 2, 6 and 7 bind to Sam68 with low affinity (Fig. 6b). This experiment provides evidence that the binding of Sam68 observed in the FMDV infection pulldown is due to binding to $3 \mathrm{D}^{\mathrm{pol}}$ involving amino acid residues found in frag- 4 and frag- 8 .

Furthermore, we used molecular docking software to illustrate the putative interaction between $3 \mathrm{D}^{\mathrm{pol}}$ and Sam68 (Fig. 6c). Panels i and ii show the electrostatic surfaces of $3 \mathrm{D}^{\mathrm{pol}}$ and Sam68, respectively, in binding pose. The electronegative surface reflected in the form of red colored bottom surface of $3 \mathrm{D}^{\mathrm{pol}}$ and blue electropositive surface of Sam68 appear to participate a strong electrostatic attraction between the two molecules shown in panel iii. Panel iv shows the docked $3 D^{\text {pol }}$ (green)-Sam68 (blue) complex in cartoon mode. Frag-4 residues 193-217 shown in orange color and frag- 8 residues 453-470 in red color form the major Sam68 binding interface in $3 \mathrm{D}^{\mathrm{pol}}$. Although, frag-5 residues 221, 222, 225, 226 also align the Sam68 binding interface, the major participation in the binding comes from frag-4 and 8, consistent with the peptide library ELISA data, further reinforcing the importance of these two regions in FMDV $3 D^{\text {pol }}$ in interaction with Sam68. The fact that Sam68 has been shown to interact with other picornaviruses and that $3 \mathrm{D}^{\mathrm{pol}}$ structure is largely preserved among picornaviruses, there might exist a common mechanism by which Sam68 affects picornavirus replication. Together the data from IP, ELISA and computational docking suggest that Sam68 binds to FMDV 3D ${ }^{\text {pol }}$ including residues contained in frag- 4 and frag- 8 .

Finally, given our previous report indicating the cleavage of Sam68 by FMDV 3C ${ }^{\text {pro }}$ as infection progressed, we wanted to ascertain if Sam68 could be similarly coprecipitated with $3 \mathrm{C}^{\mathrm{pro}}$ as was observed with $3 \mathrm{D}^{\mathrm{pol}}$. Mock-infected or FMDV-infected cells at a MOI of 10 were lysed at 1, 3, and 5 hpi. The resulting cell lysates were subject to IP with mouse monoclonal anti-FMDV $3 C^{\text {pro }}$, and the eluates thereof were probed with rabbit polyclonal anti-Sam68 (N-terminal) on a Western blot.
A strongly reacting band at $68 \mathrm{kDa}$ was detected at 5 hpi with a few lower molecular weight fragments faintly reacting, as well as a faint $68 \mathrm{kDa}$ band at $3 \mathrm{hpi}$ (Fig. $6 \mathrm{~d}$, left panel). To determine if the co-precipitation of Sam68 and $3 \mathrm{C}^{\text {pro }}$ was coincident with the appearance of cytoplasmic Sam68 degradation products, the cytoplasmic fraction of mock-infected and FMDV-infected cells at 1, 3, and 5 hpi were examined by Western blot probing with antiSam68 (N-terminal), which revealed the appearance of Sam68 cleavage fragments at 5 hpi coincident with the binding interaction between Sam68 and 3C ${ }^{\text {pro }}$ (Fig. 6d, right panel). It is noteworthy that under the conditions of this assay we cannot rule out the possibility that Sam68 may bind the unprocessed $3 \mathrm{CD}$ precursor protein through it predicted interaction with $3 \mathrm{D}^{\mathrm{pol}}$. Also, these findings are in agreement with those presented in Fig. 1, where partial re-localization of Sam68 from the nucleus to the cytoplasm is detected in cells also staining positive for FMDV proteins. We conclude that the nucleocytoplasmic movement of Sam68 and its subsequent interaction with $3 C^{\text {pro }}$ and $3 \mathrm{D}^{\mathrm{pol}}$ are important steps in the progression of FMDV infection.

\section{Discussion}

Picornaviruses are small, cytoplasmic, positive-sense RNA viruses with a simplified life cycle. The organization of cellular organelles and the sub-cellular localization of proteins change as picornavirus infection progresses. Such changes influence virus replication as well as cellular processes such as, trafficking along the membranes of these compartments and evasion to the host immune responses $[75,76]$. Among known host proteins that appear to be involved in the progression of virus infection, Sam68 exhibits increased cytoplasmic accumulation in host cells infected with picornaviruses including: PV, FMDV, EV-71, and HRV [13, 14, 76-78]. In this study, we examined the nucleocytoplasmic movement of Sam68 and its interaction with viral factors to gain a better understanding of its role in the progression of FMDV infection.

Viruses shutoff the host protein translation and exploit the cell translational machinery for the maximal translation of their own (viral) proteins and to evade the host defense mechanisms [79]. The assembly of ribosomal initiation complex and ancillary factors on the IRES precedes the ribosomal scanning for initiation codon in FMDV RNA. Many cellular proteins reportedly bind the FMDV IRES but only a handful has been demonstrated to play a role in translation [80-82], suggesting that this is still an unresolved observation. The evidence presented in the current study suggests that RNA containing RAAA sequences in FMDV IRES domains 3 and 4 are important for binding of Sam68. In EMSA competition experiments, both IRES domain 3 and 4 of IRES 
(added in 10-fold molar excess) were capable of fully disrupting the RNP complexes formed by labeled domain 4 probe and Sam68. It could be argued that the interference caused by IRES domain 3 (with CAAA motif in its apical region) could be the result of a direct competition for Sam68 binding or be due to distant RNA-RNA interactions causing a disruption on complexes formed between Sam68 and IRES domain 4. We cannot completely exclude the possibility of Sam68 involvement in stabilizing or modulating long-range IRES RNA-RNA interactions between domain 3 and 4 [12, 83, 84]. Consistent with our findings, Lin et al. [36] had reported that UAAA and to less extend the RAAA sequences are suitable binding motifs for Sam68 protein. It is important to note that the nucleic acid binding cleft of the $\mathrm{KH}$ domain containing RNA binding proteins can accommodate only four unpaired bases [85]. Indeed, the RAAA sequence motifs in FMDV IRES domains 3 and 4 described herein are predicted to be contained in stretches of very small-unpaired RNA segments and could perfectly be accommodated in the RNA binding cleft of Sam68 KH domain. This is also supported by earlier evidence showing that Sam68 preferentially binds to single-stranded UAAA RNA motifs as evidenced by SELEX analysis and also within the 3' NTRs of retrovirus transcripts as well as certain cellular mRNAs [13, 36, 86, 87].

In light of the above-mentioned observations, we sought to explore the functional significance of the Sam68-FMDV IRES interaction in more detail. To that end, we first utilized cell-free in vitro translation-RNA replication assays, which have proven to be instrumental in defining the role of many individual host or virus proteins at the molecular level [88-91]. Our in vitro cellfree experiment using Sam68-depleted extracts, revealed a defect in FMDV RNA synthesis, but not a significant reduction on virus translation, which we did not anticipate based on earlier studies [13, 92]. We believe that other splice variants of Sam68 including SLM-1 and SLM-2 (see Results section and Additional file 1: Figure S1), which contain an intact $\mathrm{KH}$ domain, but lack the Sam68-N-terminus, are still present in the depleted extracts, and could potentially bind to the FMDV IRES. It is possible that programming of cell fee translation reactions with high RNA concentrations (500 ng per reaction) could have led to similar end-point detection of $3 \mathrm{D}^{\mathrm{pol}}$ by Western blot. Future studies using lower RNA concentration and shorter incubation times to program FMDV protein synthesis in CFEs could help resolve this issue.

Results obtained in our characterization of mutated forms of genetically engineered G-luc replicons, as well as viral genomes, provide compelling evidence for the significance of the RAAA motifs in domain 3 and 4 in FMDV IRES-driven translation. It is noteworthy that the full genome and replicon mutants exhibited impairment in their translation and replication. Interestingly, our earlier studies showing reduction in FMDV titers by Sam68 siRNA knockdown and the results described herein, suggest that it is possible that subtle modifications in the Sam68 interaction with the FMDV IRES could impact other functions that this protein exerts that are needed for efficient virus replication. This supposition is in line with multi-functional properties attributed to Sam68 (see Background). Indeed, Sam68 exhibits specific binding to FMDV $3 C^{\text {pro }}$ and $3 \mathrm{D}^{\text {pol }}$ in infected cells. PV $3 \mathrm{D}^{\text {pol }}$ has also been shown to interact with Sam68 [14]. Using an indirect ELISA assay and $3 \mathrm{D}^{\mathrm{pol}}$ fragments, it was suggested that $3 \mathrm{D}^{\mathrm{pol}}$ frag-4 (aa 158-217) and frag8 (aa 405-470) bind Sam68 with high affinity. However, under the experimental conditions, we cannot exclude the possibility that frag-2 (aa 49-108), frag-6 (aa 269331 ), and frag-7 (aa 332-404) could also provide a Sam68 binding interface. In fact, the docking poses of the electrostatic surfaces of FMDV 3D ${ }^{\mathrm{pol}}$ [Fig. 6c (i)] and Sam68 [Fig. 6c (ii)] clearly indicate that the two proteins share a large interfacial area that could be shared by more than one domain in either protein. In particular, the Sam68 binding interface of $3 \mathrm{D}^{\mathrm{pol}}$ is formed by aa 193-217 and aa 453-470 in frag-4 and 8 that are part of the functionally critical palm and thumb domains of $3 \mathrm{D}^{\text {pol }}$ Fig. 6c (i). The $3 \mathrm{D}^{\mathrm{pol}}$ structure consisting of thumb, palm, finger and fingertips domains is conserved among picornaviruses. Another striking feature of the Sam68-3D $\mathrm{D}^{\mathrm{pol}}$ interaction is the charge complementarities between the binding surfaces of the two proteins (electro-negative of $3 \mathrm{D}^{\mathrm{pol}}$ and electro-positive of Sam68). Further studies will be required to determine the significance of these protein interactions for viral infection.

The observation that Sam68 co-precipitates with both the FMDV $3 \mathrm{C}^{\mathrm{pro}}$ and $3 \mathrm{D}^{\mathrm{pol}}$ also raises additional questions regarding the FMDV-induced cleavage of Sam68. The FMDV $3 D^{\mathrm{pol}}$ and transiently expressed $3 C D$ precursor are known to partially localize to the cell nucleus due to a nuclear localization signal in the $\mathrm{N}$-terminus of $3 \mathrm{D}^{\mathrm{pol}}$ [93-95]. This was the basis of our speculation that the coincident nuclear efflux of Sam68 with the observed FMDV-induced cleavage was due to the maturation of $3 \mathrm{C}^{\text {pro }}$ from nuclear-localized $3 \mathrm{CD}$ precursor [13]. The $3 C^{\text {pro }}$ cleavage of host cell transcription factors found in the nucleus of PV-infected cells also supports this notion [54]. Therefore, given Sam68 can interact with both $3 C^{\text {pro }}$ and $3 \mathrm{D}^{\mathrm{pol}}$, it remains to be determined whether WT full-length Sam68 is cleaved by FMDV $3 \mathrm{CD}$ or fully matured $3 \mathrm{C}^{\mathrm{pro}}$. Moreover, since we also observe by Western blot some accumulation of full-length Sam68 in the cytoplasm as FMDV infection progresses, it is undetermined whether the full-length or cleaved form of Sam68 contributes to the modulation in virus 
replication. Like the full-length Sam68, the $3 C^{\text {pro }}$ cleaved Sam68 is predicted to maintain its RNA-binding $\mathrm{KH}$ domain. Potentially, the C-terminal cleavage eliminates steric hindrances allowing for tighter binding.

The significance of the appearance of Sam68 truncation products as FMDV infection progresses still remains to be determined, yet the significance of Sam68 to HIV infection has been highlighted by how a Sam68 isoform with a C-terminal deletion (Sam68DeltaC) potently inhibits the progression of HIV infection [17, 30]. Sam68DeltaC reportedly represses translation of HIV genes by several mechanisms including sequestration of HIV transcripts to perinuclear bundles (PBs) and SGs as well as blocking the association of PABP1 with the 3' end of the viral transcripts [22, 23, 32, 61]. Thus, there are two interesting parallels between our findings and effects of Sam68 on HIV: first, that FMDV stimulates the association of Sam68 with at least one marker of SGs in the cytoplasm; and second, that Sam68 affects the synthesis of viral RNA in vitro in the cell-free system. Interestingly, Piotrowska et al. [16] postulated that Sam68 is a virus infection specific marker of SGs. Consistent with our findings, White et al. reported the formation and subsequent disappearance of SGs as a result of PV infection [96]. Given the translation and replication arrest attributed to RNA transcripts sequestered in SGs and that Sam68 potently stimulated FMDV RNA replication, it seems likely that the FMDV RNA is similarly excluded from SGs.

\section{Conclusions}

Sam68 is a host factor co-opted by FMDV during infection of susceptible host cells. As infection progresses, Sam68 becomes partially redistributed to the cytoplasm, where earlier in infection, it co-localizes with markers of SGs. Interaction of Sam68 with the FMDV IRES appears to promote viral RNA translation in vitro. Disruption of the IRES RAAA motif leads to non-viable virus progeny and defective replicons, though this may not be attributable to Sam68 interaction with the IRES alone. Finally, consistent with a role in RNA replication and its observed cleavage during FMDV infection, Sam68 co-precipitates with both FMDV $3 \mathrm{C}^{\mathrm{pro}}$ and $3 \mathrm{D}^{\mathrm{pol}}$.

\section{Methods}

\section{Materials}

Stratagene QuickChange IIXL mutagenesis kit was purchased from Agilent Technologies, Inc. (Santa Clara, CA). Lipofectamine 2000 DNA transfection reagent and streptavidin-coupled magnetic beads were purchased from Invitrogen (Carlsbad, CA). Sam68 expression plasmids pGEX-2 T Sam68 (Containing GST-tagged Sam68), pcDNA3 HA-tagged Sam68-WT and pcDNA3 HA-tagged Sam68 delta-KH (Sam68-KH-del) were purchased from
Addgene Cambridge, MA, USA. LightShift ${ }^{\bullet}$ Chemiluminescent RNA EMSA Kit and the NE-PER cellular fractionation kit were purchased from Thermo Fisher Scientific Inc. (Rockford, IL). Restriction enzymes EcoRI and BamHI were purchased from New England Biolabs (Ipswich, MA).

\section{Antibodies}

Polyclonal rabbit anti-Sam68 directed against the Cterminus of Sam68 (C-20), polyclonal goat anti-TIA-1, and HA-probe Antibody (F-7) were purchased from Santa Cruz Biotechnology (Santa Cruz, CA). Mouse monoclonal anti-G3BP was purchased from Abcam (Cambridge, MA). Polyclonal rabbit anti-Sam68 directed against the Nterminus of Sam68 was purchased from Novus Biologicals (Littleton, CO). Monoclonal mouse anti-FMDV $3 \mathrm{D}^{\text {pol }}$ antibody was a gift from Dr. A. Clavijo at the National Centre for Foreign Animal Disease, Winnipeg, Manitoba, Canada. Rabbit polyclonal anti-VP1 sera were courteously provided by Dr. M. Grubman, ARS, USDA. Goat-antirabbit antibodies conjugated to AlexaFluor-488 (AF-488), donkey-anti-goat antibodies conjugated to AF-568 and goat-anti-mouse antibodies conjugated to AF-568 were purchased from Molecular Probes (Carlsbad, CA).

\section{Viruses, cell lines, plasmids and PCR primers}

FMDV type $\mathrm{A}_{24}$ Cruzeiro/Brazil $1955\left(\mathrm{~A}_{24} \mathrm{Cru}, \mathrm{Gb}, \mathrm{Acc}\right.$ \#AY593768) was derived from the infectious cDNA clones $\mathrm{pA}_{24} \mathrm{Cru}$ [97]. FMDV $\mathrm{A}_{24}$ Cru carrying modified IRES (Table 1) with abrogated Sam68 binding sites were produced by site directed mutagenesis of full-length genome copy plasmid $\mathrm{pA}_{24}$ Cru. The LFBK, LFBK- $\alpha \mathrm{v} \beta 6$ and IBRS2 cell lines were cultured in $10 \%$ fetal bovine serum (FBS) in Dulbecco's minimal essential media (DMEM) supplemented with antibiotic/antimycotic $[55,56]$. Cells were grown at $37^{\circ} \mathrm{C}$ in a humidified $5 \% \mathrm{CO}_{2}$ atmosphere. All of the PCR primers used to generate different clones and mutations were purchased from Life Technologies (Carlsbad, CA). The primer sequences have been detailed in Table 1. GST-tagged Sam68 clone was purchased from Addgene (Cambridge, MA). Sam68-6H was prepared by sub-cloning the Sam68 coding gene between EcoRI and BamHI sites in pET30C+ vector from pGEX2 T Sam68 for E. coli expression.

\section{Plasmid transfection}

Mammalian cells were transfected with plasmid DNA using the Lipofectamine 2000 transfection reagent (Invitrogen) following the manufacturer's protocol. Briefly, cells were grown to approximately $30-40 \%$ confluence. The cell culture medium was replaced with serum-free media containing the desired plasmid and Lipofectamine 2000. Cells were incubated with the mixture for $48 \mathrm{~h}$ at $37{ }^{\circ}$ C. Post-incubation, the cells were harvested for 
examination by Western blot to confirm expression of the desired construct.

\section{Immunofluorescent microscopy (IFM)}

Cells were grown on glass coverslips in 12-well plates until approximately $40 \%$ confluence. Control uninfected cells were fixed immediately with $4 \%$ paraformaldehyde [98] in PBS for $10 \mathrm{~min}$ (min) at room temperature (RT) prior to the introduction of virus into adjacent wells. After fixation of the control cells, the remaining wells containing cells on coverslips were infected with WT FMDV $\mathrm{A}_{24}$ Cru at a MOI of 10 and incubated at $37{ }^{\circ} \mathrm{C}$ for $1 \mathrm{~h}$. Excess virus was removed by acid-washing the cells briefly followed by three rinses with virus growth media (VGM). Designated cells were then fixed with $4 \%$ $\mathrm{PF}$, representing a $1 \mathrm{hpi}$ time point. Remaining cells were provided fresh VGM and incubated for 2, 3, 4, or $5 \mathrm{hpi}$ at $37{ }^{\circ} \mathrm{C}$, after which, they were fixed with $4 \% \mathrm{PF}$. Cells were washed in PBS, permeabilized with $0.1 \%$ TritonX100 in PBS for 20 min on ice, and blocked with $3 \%$ bovine serum albumin (BSA) for $30 \mathrm{~min}$ at RT. The cells were probed with primary antibodies at RT for $1 \mathrm{~h}$. The following day the cells were incubated for $1 \mathrm{~h}$ at RT with goat-anti-rabbit and goat-anti-mouse conjugated with AF-488 or AF-568 (Molecular Probes), respectively. The cover slips were washed three times with PBS after each antibody treatment. After the final antibody treatment, the cover slips were air-dried and mounted onto glass slides with ProLong antifade medium supplemented with DAPI stain (Life Technologies). Cells were examined and images captured using a 100X oil immersion objective on an Olympus fluorescent microscope (Center Valley, PA). Images were refined and figures generated using Adobe Photoshop software (Adobe Systems Incorporated, San Jose, CA). When examining cells transfected with GFP-tagged Sam68, the permeabilization and subsequent antibody steps were omitted. Following fixation and PBS washes, the coverslips of the transfected cells were mounted using ProLong anti-fade with DAPI and examined as described above.

\section{Western blot}

SDS-PAGE (sodium dodecyl sulfate-polyacrylamide gel electrophoresis) was carried out using a $12 \%$ Nu-PAGE ${ }^{\circ}$ pre-cast gel system (Invitrogen). Subsequently, the separated proteins were electro-blotted onto a nitrocellulose membrane (Sigma-Aldrich, Saint Louis, MO). After blocking the membrane with $5 \%$ milk in PBS-T, specific proteins were detected with primary antibodies at indicated dilutions followed by goat-anti-rabbit or goat-antimouse antibodies conjugated with HRP (Sigma-Aldrich). Cellular $\alpha$-tubulin, employed as an internal loading control protein, was detected with mouse monoclonal antitubulin antibody (1:10,000 dilution) that in turn was detected with (1: 20,000) goat anti mouse-HRP (SigmaAldrich). The bound HRP conjugate antibodies were reacted with the WestDura SuperSignal chemiluminescent reagent (Pierce) according to the manufacturer's instructions and visualized on X-ray film (X-Omat; Kodak, NY).

\section{Cloning expression and purification of recombinant Sam68-6H}

In order to generate hexahistidine $(6 \mathrm{H})$ fused-Sam68 (Sam68-6H), the Sam68 coding gene was sub-cloned into pET30c + plasmid from pGEX-2 T Sam68 plasmid using BamHI and EcoRI restriction sites. Rosetta-DE3 cells were transformed with Sam68-6H-pET30c + plasmid. Single colony containing the plasmid was inoculated in $100 \mathrm{~mL}$ LB broth containing $0.4 \%$ glucose, $25 \mu \mathrm{g} / \mathrm{mL}$ kanamycin (K25) and $20 \mu \mathrm{g} / \mathrm{mL}$ chloramphenicol (C20), and grown at $30^{\circ} \mathrm{C}$ with $220 \mathrm{rpm}$ rotor speed in a Thermo Scientific MaxQ 4000 benchtop orbital shaker. This overnight culture was used as a starter culture for 11 (L) LB K-25, C-20 broth at $37^{\circ} \mathrm{C}$. At an OD of 0.8 , the culture was induced with $1 \mathrm{mM}$ IPTG for $3 \mathrm{~h}$. The cell pellets were harvested by centrifugation at $4000 \mathrm{rpm}$ at $4{ }^{\circ} \mathrm{C}$ in a Sorvall high-speed centrifuge. Sam68-6H was lysed for $20 \mathrm{~min}$ at RT with intermittent stirring in BugBuster ${ }^{\text {To }}$ cell lysis reagent supplemented with pepstatin and leupeptin. To disrupt the cellular nucleic acids cell lysate was then sonicated at $85 \%$ slope for $5 \mathrm{~min}$ at $30 \mathrm{~s}$ intervals. After centrifugation of the lysates for $30 \mathrm{~min}$ at $12,500 \mathrm{rpm}$ at $4^{\circ}$ $\mathrm{C}$, the supernatant was mixed with $5 \mathrm{~mL} \mathrm{Ni-NTA}$ agarose slurry pre-equilibrated with $6 \mathrm{H}$-binding buffer (Pierce) and incubated at RT with gentle shaking. This slurry was packed in a polypropylene column and eluted with 5 column volumes of $6 \mathrm{H}$-elution buffers (Pierce). The fractions with highest protein purity were pooled and dialysed against $50 \mathrm{mM}$ Tris- $\mathrm{HCl} \mathrm{pH} 8.0$ containing $10 \mathrm{mM} \beta$-mercaptoethanol, $10 \%$ glycerol, pepstatin and leupeptin. Protein concentration was monitored against reagent blank at $280 \mathrm{nM}$ and the identity of protein was confirmed by Western blot using 1:500 rabbit polyclonal antibody raised against C-terminus of Sam68 (Santa Cruz Biotechnology, C-20).

\section{Expression and purification of HA-tagged Sam WT and Sam68-KH-del}

HEK-293 cells containing SV40 T-antigen (293 T cells) were either transfected with pcDNA3 HA-tagged Sam68-WT or pcDNA3 HA-tagged Sam68 delta-KH (Sam68-KH-del) using Lipofectamine-2000 reagent. After $48 \mathrm{~h}$, the cells were lysed by incubating for $5 \mathrm{~min}$ in $1 \mathrm{X}$ NP40 lysis buffer containing $50 \mathrm{mM}$ Tris- $\mathrm{HCl}$, $\mathrm{pH} 8,150 \mathrm{mM} \mathrm{NaCl}$ and $1 \% \mathrm{NP} 40$. Following lysis, the debris were removed by centrifuging the lysate at 
$15,000 \mathrm{rpm}$ at $4{ }^{\circ} \mathrm{C}$ and $20 \mathrm{~min}$. HA-tagged Sam68-WT or Sam68-KH-del were purified using HA-tagged protein purification kit (MBL International, IL, USA) as per manufacturer's instructions. The purified proteins were diluted to 10 times their initial volume in 1X RNAEMSA buffer (Thermo Fisher Scientific, USA) and concentrated using Amicon Ultra-15 Centrifugal Filter Units with $30 \mathrm{KDa}$ cutoff (EMD Millipore, USA). The identity of proteins was confirmed by Western blot probing with HA-probe antibody (F-7, Santa Cruz Biotechnology). Purified HA-tagged Sam68-WT and Sam68-KH-del were stored at $-80^{\circ} \mathrm{C}$ until further use.

\section{Synthesis of FMDV $5^{\prime}$ NTR RNAs}

FMDV $\mathrm{A}_{24}$ Cru infectious clone linearized with restriction enzyme SwaI was utilized as template for generating various IRES domain RNAs. Full-length IRES was amplified with primer pair P1579 S IRES -T7 and P1580 AS IRES. Various IRES fragments were amplified with their respective primer pairs as following: P1329 $\mathrm{A}_{24}$-T7cre and P1330 AS cre (cre-fragment); sense (S) 5' NTR T7P1287 and antisense (AS) 5' NTR-P1288 (S-fragment); P21036 IRES loop 1-T7 and P21037 IRES loop 1 Reverse (IRES loop 1); P1584 IRES loop 2 Forward-T7 and P1585 IRES loop 2 Reverse (IRES loop 2); P21034 IRES loop 3-T7 and P21035 IRES loop 3 Reverse (IRES loop 3); P-1581-IRES-4 Forward-T7 and P-1582-IRES-4 Reverse (IRES loop 4). See Table 1 for the detailed description of primers. Phusion Hot Start II High-Fidelity PCR kit (Thermo Scientific) was used to amplify the IRES fragments. MEGAscript ${ }^{\circ}$ T7 Transcription Kit (Life Technologies) was used to synthesize the IRES RNAs. Biotinylated IRES RNAs were generated using the same T7 transcription kit with the only difference being in terms of the nucleotide tri-phosphates (NTPs). For biotinylated IRES RNA, the unlabeled NTPs were replaced with equal concentration of Roche biotin-NTP mix. RNA fragments were purified using NucAway $^{\text {ma }}$ Spin Columns (Life Technologies). The RNAs were stored at $-80^{\circ} \mathrm{C}$ until further use.

\section{Biotin RNA pull-down assay}

Biotinylated FMDV IRES full length, domain 2, domains 2-4, and domain 4 RNA were transcribed using the Megascript T7 kit (Ambion) with rNTPs supplemented with biotin-11-CTP (Roche). First, $50 \mu \mathrm{L}$ of streptavidinM280 magnetic beads (Invitrogen) were pulled-down by a magnet and equilibrated in $1 \mathrm{~mL}$ of $1 \mathrm{X}$ binding and washing (B\&W) buffer consisting of $5 \mathrm{mM}$ Tris $-\mathrm{HCl}$, $\mathrm{pH} 7.5,0.5 \mathrm{mM}$ EDTA, and $1 \mathrm{mM} \mathrm{NaCl}$. Following another pulldown and removal of B\&W buffer, $5 \mu \mathrm{g}$ of recombinant Sam68 and $100 \mu \mathrm{g}$ of tRNA were added to the beads and incubated at $37^{\circ} \mathrm{C}$ for $30 \mathrm{~min}$ in a final volume of $200 \mu \mathrm{L} 1 \mathrm{X} \quad \mathrm{B} \& \mathrm{~W}$ buffer. The beads with potentially bound RNA and protein were pulled-down and washed three times in B\&W buffer. Finally, the beads were resuspended in $20 \mu \mathrm{L}$ of $1 \mathrm{X}$ Laemmli sample buffer, heated at $98^{\circ} \mathrm{C}$ for $10 \mathrm{~min}$, and the supernatant collected after centrifugation was loaded onto a $12 \%$ SDS-PAGE gel followed by Western blot analysis probing with antiSam68 (Santa Cruz Biotechnology).

\section{Electrophoretic mobility shift assay (EMSA)}

Sixty five nucleotide long 5 '-biotin labeled synthetic RNA probe containing two potential Sam68 binding (UAAA) motifs in WT form (labeled as WT domain 4 probe) or mutated form (UACG) labeled as (mutant domain 4 probe) were purchased from Integrated DNA Technology (IDT, Coralville, IA) (See Table 1 for sequence description). The RNA binding reaction was carried out for both WT and mutant domain 4 probe for $20 \mathrm{~min}$ at $\mathrm{RT}$ in $30 \mu \mathrm{L}$ reaction volume containing $50 \mathrm{mM}$ Tris- $\mathrm{HCl}, \mathrm{pH}$ 7.9, $100 \mathrm{mM} \mathrm{NaCl}, 10 \mathrm{mM}$ $\mathrm{MgCl}_{2}, 10 \%$ glycerol, $1.0 \mathrm{mM}$ DTT, $1.0 \mu \mathrm{g} / \mu \mathrm{L}$ tRNA and different concentrations of recombinant Sam68. Protein bound RNA was resolved from the free RNA on $6 \%$ acrylamide gel in $0.5 \mathrm{X}$ TBE buffers for $90 \mathrm{~min}$ at 60 volt (V) and $4{ }^{\circ} \mathrm{C}$, which was pre-run for $1 \mathrm{~h}$ at $60 \mathrm{~V}$ to maintain uniform current. RNA were transferred from gel to precharged Hybond nylon membrane at $30 \mathrm{~V}$ (constant voltage) for 45 min using NuPAGE ${ }^{\oplus}$ Novex $^{\circ}$ trans-blot apparatus (Life Technologies) in the presence of $0.5 \mathrm{X}$ TBE buffer. After the RNA were transferred to the nylon membrane, the RNA were crosslinked to the membrane using $2000 \mathrm{MJ}-\mathrm{cm}^{-2}$ ultraviolet radiation twice in Stratalinker UV-crosslinking system (Stratagene). The RNA was detected with LightShift Chemiluminescent EMSA Kit (Pierce) following the manufacturer's instructions.

\section{Co-immunoprecipitation of FMDV $3 C^{\text {pro }}$ and $3 D^{\text {pol }}$ with Sam68}

Following the manufacturer's protocol, antibodies directed against FMDV $3 C^{\text {pro }}$ or $3 \mathrm{D}^{\text {pol }}$ or Sam68 were separately bound and crosslinked to the Protein G Dynabeads (Novagen) using the reagents provided in the Pierce Crosslink Co-immunoprecipitation Kit (Pierce). BHK-21 cells uninfected or infected with FMDV for $4 \mathrm{~h}$ were lysed with 1X RIPA buffer ( $1 \%$ NP40, $0.5 \%$ sodium deoxycholate, $0.1 \%$ SDS, and $1 \mathrm{X}$ PBS) supplemented with proteinase inhibitors and Benzonase ${ }^{\text {Tw }}$ (Novagen, Gibbstown, NJ). Approximately 1-5 mg of uninfected or virus-infected cell lysates were then mixed with different sets of antibody-coupled beads, washed, and eluted. IP eluates were mixed with Laemmli sample buffer [99] boiled, and analyzed by Western blot probing with antibodies against Sam68 (Abnova) or FMDV $3 D^{\text {pol }}$. 
FMDV $3 D^{\text {pol }}$ peptide library ELISA to determine Sam68 binding segment of $3 \mathrm{D}^{\text {pol }}$

A sandwich ELISA was performed where recombinant Sam68 was diluted in buffer carbonate-bicarbonate ( $\mathrm{pH}$ 9.6) to obtain $0.05 \mu \mathrm{g} / \mathrm{mL}$, and $100 \mu \mathrm{L} /$ well was used to coat Nunc Maxisorp plates (Fisher Scientific). After overnight incubation at $4^{\circ} \mathrm{C}$, the plates were washed on plate washer (SkanWasher 300 Version B) with $0.01 \mathrm{M}$ PBS and $0.05 \%$ Tween 20 (PBS-T). Next, individual 6 His-tagged $3 \mathrm{D}^{\mathrm{pol}}$ fragments were diluted to $10 \mathrm{ng} / \mathrm{mL}$, whereas 6 His-tagged full-length $3 \mathrm{D}^{\mathrm{pol}}$ was diluted to $500 \mathrm{ng} / \mathrm{mL}$ in blocking buffer and added to the plate, followed by incubation at $37^{\circ} \mathrm{C}$ for $1 \mathrm{~h}$ on a rotary shaker followed by washing on plate washer (SkanWasher 300 Version B) with $0.01 \mathrm{M}$ PBS and $0.05 \%$ Tween 20 (PBS-T). One hundred $\mu \mathrm{L}$ of anti-6His was added at 1/500 dilution in blocking buffer followed by incubating the plate at $37^{\circ} \mathrm{C}$ for $1 \mathrm{~h}$ while shaking. The plate was washed using the plate washer (SkanWasher 300 Version B). One hundred $\mu \mathrm{L}$ of HRP (SureBlue-KPL) was added, and after about $10 \mathrm{~min}$ when the blue color developed in the positive wells, the reaction was stopped by adding $100 \mu \mathrm{L}$ of SureBlue-KPL stop solution and read in the plate reader, Biotek ELx808 at $640 \mathrm{~nm}$.

\section{Computational prediction and docking of 3D structure of FMDV $3 D^{\text {pol }}$ and Sam68}

For this purpose, first, the structural model of full-length Sam68 was made using Phyre-2.0 web server [100] and FMDV $_{24} 3 \mathrm{D}^{\mathrm{pol}}$ using SWISS-MODEL [101]. These initial structures were energy minimized by hybrid molecular mechanics/molecular dynamics protocol in which first 1000 steps of energy minimization using replica exchange protocol. Finally, FMDV $\mathrm{A}_{24} 3 \mathrm{D}^{\mathrm{pol}}$ and Sam68 were docked with Clus-Pro docking interface [102] and 20 binding poses were analyzed and the most common pose was selected for analysis of contact interface and bonding between the two proteins.

Preparation of cell-free extract (CFE), Sam68 depletion, in vitro translation and synthesis of viral RNA

FMDV $A_{24}$ RNA was transcribed from FMDV $A_{24}$ plasmid linearized with the restriction enzyme SwaI. The CFE of BHK-21 cells were prepared with modifications to the protocol described earlier [88, 103]. Briefly, a $1.8 \mathrm{~L}$ culture of BHK-21 cells was harvested and lysed in the presence of 1.5 volumes of hypotonic K-HEPES buffer $\mathrm{pH} 7.4$ to 1 volume of packed cells to the cell. The lysates were prepared, cleared of debris, and treated with micrococcal nuclease in the presence of $0.75 \mathrm{mM} \mathrm{CaCl}_{2}$ and $25{ }^{\circ} \mathrm{C}$ for $30 \mathrm{~min}$. After this, the nuclease was inactivated with $3 \mathrm{mM}$ EGTA, pH 8. Sam68 depletion was performed by mixing $100 \mu \mathrm{L}$ of rabbit polyclonal anti Sam68 antibody (NBP1-80229, Novus Biological) with
$1 \mathrm{~mL}$ of BHK-21 CFE and $50 \mu \mathrm{L}$ Dynabeads protein $\mathrm{G}$ for $2 \mathrm{~h}$ at room temperature under gentle rotation. Following incubation, the mix was put on magnetic plate to separate the bead bound material (anti-Sam68 antibodySam68 protein). The clear supernatant was labeled as Sam68 depleted CFE, and used later for protein and RNA synthesis experiments. The FMDV $A_{24}$ RNA synthesis, the effect of Sam68 on this process, and the detection of newly synthesized RNA were carried with following modifications to the protocol described by Pogany and Nagy [90]: 1) instead of using $\mathrm{P}^{32}$ labeled nucleotides, biotin-UTP was used to detect the newly synthesized RNA, 2) purified viral polymerase was used to initiate the polymerase reaction, and 3 ) the reaction was carried out at $37^{\circ} \mathrm{C}$ for $5 \mathrm{~h}$. The newly synthesized RNA was spotted on pre-charged Hybond nylon membrane followed by detection of the signal with the Pierce nucleic detection kit following the manufacturer's protocol. The translation reactions were carried out in CFE containing 20 amino-acyl tRNAs creatinine phosphate, creatine kinase, dTT, rATP, rGTP, rCTP, and rUTP at $32{ }^{\circ} \mathrm{C}$ with aliquots collected at $30 \mathrm{~min}, 60 \mathrm{~min}, 90 \mathrm{~min}$ and $120 \mathrm{~min}$, which were resolved on 4-12 \% SDS gel, and detected by Western blot probing with antiFMDV $3 \mathrm{D}^{\mathrm{pol}}$.

\section{Construction of IRES mutant FMDV $\mathrm{A}_{24}$ Cru full genome and G-luciferase (G-luc) replicon plasmids}

CAAA to CACG mutation in domain 3 was introduced by sub-cloning the regions with desired mutations I 3: CAAA to CACG, I 4: UAAA.....UAAA to UACG...... UACG, and I 34: CAAA....UAAA......UAAA to CACG... UACG.....UACG mutations from synthetic DNAs containing the mutations spanning SanDI and $\mathrm{XbaI}$ sites (purchased from Biobasic Inc.). The parental $\mathrm{A}_{24} \mathrm{Cru}$ full genome plasmid clone was digested with restriction enzymes SanDI and $\mathrm{XbaI}$ and the fragments purified. Using Infusion primer pairs P-2182-Infusion-FMDV $\mathrm{A}_{24}$ IRES Forward and P-2183-Infusion-FMDV $\mathrm{A}_{24}$ IRES Reverse (Table 1), the mutant DNA was PCR-amplified with Phusion high fidelity PCR kit and subsequently SanDI/ $\mathrm{XbaI}$ digested and cloned into the backbone using Infusion HD cloning kit (Clontech). The identities and integrity of the clones were confirmed by full genome sequencing.

\section{Construction of the $\mathrm{A}_{24}$ replicons containing the G-luciferase (G-luc) reporter}

The IRES mutant FMDV replicons were created by substituting the BstEII-M $f e$ I digested DNA fragments containing IRES mutations into a $\mathrm{pA}_{24}$ G-luc replicon system (Kloc et al., submitted as a separate manuscript). Briefly, these replicons were derived by replacing the $\mathrm{L}^{\text {pro }}$, and capsid coding sequences with a G-luciferase reporter gene, and later sub-cloning the IRES mutations 
into the $\mathrm{A}_{24} \mathrm{G}$-luc plasmid. The new constructs were labeled as: I3 G-luc, I4 G-luc and I34 G-luc. The RNAs were derived from either SwaI or MfeI digested plasmids and then transfected into BHK-21 cells using Lipofectamine 2000 transfection reagent (Life Technologies). The cell lysate obtained from samples collected at 0, 2, 6 and 24 hpt were clarified and the G-luc signal was assessed using a Microplate Luminometer. The G-luc signals were normalized to the amount total protein measured in each individual lysate. Two independent transfection experiments were conducted for each of the RNA and the G-luc values are expressed as relative luciferase units (RLU) per nanogram of protein.

\section{Additional file}

Additional file 1: Figure S1. Sam68 truncated related proteins SLM-1 and SLM-2 maintain RNA-binding domains. A. Schematic of the alignment of full-length Sam68, Sam68-like molecule 1 (SLM-1), and SLM-2. The KH domain and the $\mathrm{N}$ - and $\mathrm{C}$-terminal $\mathrm{KH}$ domains (NK, CK) embedded in the larger GSG domain is indicated. Also shown is the nuclear localization sequence (NLS), poly-tyrosine region (Poly Y), and multiple poly-proline regions (P1-P6). B. Clustal-Omega amino acid sequence alignment of human Sam68 (Acc \#Q07666.1), SLM-1 (AcC \#Q5WWX1.1), and SLM-2 (Acc \#O75525.1). The RNA-binding KH domain is indicated by bolded and underlined letters and shaded background. (PPTX $56 \mathrm{~kb}$ )

\section{Competing interests}

The authors of this research manuscript declare that they have no competing interests.

\section{Authors' contributions}

DR: performed all of the Sam68-FMDV RNA-binding experiments, conducted all of the experiments using the in vitro cell-free system, tested for FMDV virus translation and RNA replication activity, immunofluorescent microscopy experiments showing Sam68 redistribution in LFBK aVB6, IBRS2 cell lines and performed the Sam68-FMDV 3D ${ }^{\text {pol }}$ biochemical and structural analyses. PL: performed the most of the immunofluorescent microscopy experiments in the article, tested the interaction of Sam68 with FMDV 3C ${ }^{\text {pro }}$, and conducted the cytoplasmic fractionation experiment examining Sam68 localization and proteolysis post-FMDV infection. Both DR and PL contributed equally to the preparation of this research manuscript and the preparation of the figures and tables. ES: maintained the cell lines used in these studies, conducted the viral infections, and assisted in the generation of the RNAs assayed here. AK: contributed to the site directed mutagenesis for IRES mutant constructs and is principally responsible for the development and implementation of the G-luc system described herein and elsewhere. ER: conceived the study and overviewed its design, implementation, and coordination. All of the authors have reviewed and approved the final version of this manuscript.

\section{Acknowledgements}

This research was supported by CRIS project number 1940-32000-057-00D, Agricultural Research Service [22], United States Department of Agriculture (USDA, to Dr. Elizabeth Rieder). Drs. Devendra K. Rai and Paul Lawrence received a fellowship by the Plum Island Animal Disease Research Participation Program administered by the Oak Ridge Institute for Science and Education (ORISE) through an interagency agreement between the U.S. Department of Energy and the USDA. We thank Dr. Alfonso Clavijo for the gift of mAbs 40 C8 and F32-44; and Sarah Conderino and Traci Turecek for technical assistance.

Received: 7 August 2015 Accepted: 10 December 2015 Published online: 23 December 2015

\section{References}

1. Rodriguez LL, Gay CG. Development of vaccines toward the global control and eradication of foot-and-mouth disease. Expert Rev Vaccines. 2011;10(3):377-87.

2. Grubman MJ, Baxt B. Foot-and-mouth disease. Clin Microbiol Rev. 2004; 17(2):465-93.

3. Mason PW, Grubman MJ, Baxt B. Molecular basis of pathogenesis of FMDV. Virus Res. 2003;91(1):9-32.

4. Pelletier J, Sonenberg N. Internal initiation of translation of eukaryotic mRNA directed by a sequence derived from poliovirus RNA. Nature. 1988; 334(6180):320-5.

5. Jang SK, Krausslich HG, Nicklin MJ, Duke GM, Palmenberg AC, Wimmer E. A segment of the 5' nontranslated region of encephalomyocarditis virus RNA directs internal entry of ribosomes during in vitro translation. J Virol. 1988;62(8):2636-43.

6. Hellen CU, Sarnow P. Internal ribosome entry sites in eukaryotic mRNA molecules. Genes Dev. 2001;15(13):1593-612.

7. Holcik M, Sonenberg N, Korneluk RG. Internal ribosome initiation of translation and the control of cell death. Trends Genet. 2000;16(10):469-73.

8. Pestova TV, Hellen CU, Shatsky IN. Canonical eukaryotic initiation factors determine initiation of translation by internal ribosomal entry. Mol Cell Biol. 1996;16(12):6859-69.

9. Bedard KM, Daijogo S, Semler BL. A nucleo-cytoplasmic SR protein functions in viral IRES-mediated translation initiation. EMBO J. 2007;26(2):459-67.

10. Pineiro D, Fernandez N, Ramajo J, Martinez-Salas E. Gemin5 promotes IRES interaction and translation control through its C-terminal region. Nucleic Acids Res. 2013;41(2):1017-28.

11. Yu Y, Abaeva IS, Marintchev A, Pestova TV, Hellen CU. Common conformational changes induced in type 2 picornavirus IRESs by cognate trans-acting factors. Nucleic Acids Res. 2011;39(11):4851-65.

12. Fernandez-Miragall $O$, Ramos R, Ramajo J, Martinez-Salas E. Evidence of reciprocal tertiary interactions between conserved motifs involved in organizing RNA structure essential for internal initiation of translation. RNA. 2006;12(2):223-34.

13. Lawrence $P$, Schafer EA, Rieder E. The nuclear protein Sam68 is cleaved by the FMDV 3 C protease redistributing Sam68 to the cytoplasm during FMDV infection of host cells. Virology. 2012;425(1):40-52.

14. McBride AE, Schlegel A, Kirkegaard K. Human protein Sam68 relocalization and interaction with poliovirus RNA polymerase in infected cells. Proc Natl Acad Sci U S A. 1996;93(6):2296-301.

15. McBride AE, Taylor SJ, Shalloway D, Kirkegaard K. KH domain integrity is required for wild-type localization of Sam68. Exp Cell Res. 1998;241(1):84-95.

16. Piotrowska J, Hansen SJ, Park N, Jamka K, Sarnow P, Gustin KE. Stable formation of compositionally unique stress granules in virus-infected cells. J Virol. 2010;84(7):3654-65.

17. Cochrane A. Inhibition of HIV-1 gene expression by Sam68 Delta C: multiple targets but a common mechanism? Retrovirology. 2009;6:22.

18. He JJ, Henao-Mejia J, Liu Y. Sam68 functions in nuclear export and translation of HIV-1 RNA. RNA Biol. 2009;6(4):384-6.

19. Li J, Liu Y, Kim BO, He JJ. Direct participation of Sam68, the 68-kilodalton Src-associated protein in mitosis, in the CRM1-mediated Rev nuclear export pathway. J Virol. 2002;76(16):8374-82.

20. Li J, Liu Y, Park IW, He JJ. Expression of exogenous Sam68, the 68-kilodalton SRC-associated protein in mitosis, is able to alleviate impaired Rev function in astrocytes. J Virol. 2002;76(9):4526-35.

21. Liu J, Henao-Mejia J, Liu H, Zhao Y, He JJ. Translational regulation of HIV-1 replication by HIV-1 Rev cellular cofactors Sam68, elF5A, hRIP, and DDX3. J Neuroimmune Pharmacol. 2011;6(2):308-21.

22. Marsh K, Soros V, Cochrane A. Selective translational repression of HIV-1 RNA by Sam68DeltaC occurs by altering PABP1 binding to unspliced viral RNA. Retrovirology. 2008;5:97.

23. McLaren M, Asai K, Cochrane A. A novel function for Sam68: enhancement of HIV-1 RNA 3' end processing. RNA. 2004;10(7):1119-29.

24. McLaren M, Cochrane A. Mapping of determinants involved in the stimulation of HIV-1 expression by Sam68. Virology. 2009;385(1):93-104.

25. Modem S, Badri KR, Holland TC, Reddy TR. Sam68 is absolutely required for Rev function and HIV-1 production. Nucleic Acids Res. 2005;33(3):873-9.

26. Najib S, Rodriguez-Bano J, Rios MJ, Muniain MA, Goberna R, SanchezMargalet V. Sam68 is tyrosine phosphorylated and recruited to signalling in peripheral blood mononuclear cells from HIV infected patients. Clin Exp Immunol. 2005;141(3):518-25. 
27. Reddy TR. A single point mutation in the nuclear localization domain of Sam68 blocks the Rev/RRE-mediated transactivation. Oncogene 2000;19(27):3110-4.

28. Reddy TR, Suhasini M, Xu W, Yeh LY, Yang JP, Wu J, et al. A role for $\mathrm{KH}$ domain proteins (Sam68-like mammalian proteins and quaking proteins) in the post-transcriptional regulation of HIV replication. J Biol Chem. 2002;277(8):5778-84.

29. Reddy TR, Tang H, Xu W, Wong-Staal F. Sam68, RNA helicase A and Tap cooperate in the post-transcriptional regulation of human immunodeficiency virus and type D retroviral mRNA. Oncogene. 2000;19(32):3570-5

30. Reddy TR, Xu W, Mau JK, Goodwin CD, Suhasini M, Tang H, et al. Inhibition of HIV replication by dominant negative mutants of Sam68, a functional homolog of HIV-1 Rev. Nat Med. 1999;5(6):635-42.

31. Reddy TR, Xu WD, Wong-Staal F. General effect of Sam68 on Rev/Rex regulated expression of complex retroviruses. Oncogene. 2000;19(35):4071-4

32. Soros VB, Carvajal HV, Richard S, Cochrane AW. Inhibition of human immunodeficiency virus type 1 Rev function by a dominant-negative mutant of Sam68 through sequestration of unspliced RNA at perinuclear bundles. J Virol. 2001:75(17):8203-15.

33. Huot ME, Brown CM, Lamarche-Vane N, Richard S. An adaptor role for cytoplasmic Sam68 in modulating Src activity during cell polarization. Mol Cell Biol. 2009;29(7):1933-43.

34. Huot ME, Vogel G, Richard S. Identification of a Sam68 ribonucleoprotein complex regulated by epidermal growth factor. J Biol Chem. 2009;284(46):31903-13.

35. Lazer G, Pe'er L, Schapira V, Richard S, Katzav S. The association of Sam68 with Vav1 contributes to tumorigenesis. Cell Signal. 2007;19(12):2479-86.

36. Lin Q, Taylor SJ, Shalloway D. Specificity and determinants of Sam68 RNA binding. Implications for the biological function of $\mathrm{K}$ homology domains. J Biol Chem. 1997;272(43):27274-80.

37. Lukong KE, Larocque D, Tyner AL, Richard S. Tyrosine phosphorylation of sam68 by breast tumor kinase regulates intranuclear localization and cell cycle progression. J Biol Chem. 2005;280(46):38639-47.

38. Lukong KE, Richard S. Sam68, the KH domain-containing superSTAR. Biochim Biophys Acta. 2003;1653(2):73-86.

39. Lukong KE, Richard S. Breast tumor kinase BRK requires kinesin-2 subunit KAP3A in modulation of cell migration. Cell Signal. 2008;20(2):432-42.

40. Nakka KK, Chaudhary N, Joshi S, Bhat J, Singh K, Chatterjee S, et al. Nuclear matrix-associated protein SMAR1 regulates alternative splicing via HDAC6-mediated deacetylation of Sam68. Proc Natl Acad Sci U S A. 2015;112(26):E3374-83.

41. Paronetto MP, Messina V, Bianchi E, Barchi M, Vogel G, Moretti C, et al. Sam68 regulates translation of target mRNAs in male germ cells, necessary for mouse spermatogenesis. J Cell Biol. 2009:185(2):235-49.

42. Ramakrishnan P, Baltimore D. Sam68 is required for both NF-kappaB activation and apoptosis signaling by the TNF receptor. Mol Cell. 2011;43(2):167-79.

43. Resnick RJ, Taylor SJ, Lin Q, Shalloway D. Phosphorylation of the Src substrate Sam68 by Cdc2 during mitosis. Oncogene. 1997:15(11):1247-53.

44. Taylor SJ, Resnick RJ, Shalloway D. Sam68 exerts separable effects on cell cycle progression and apoptosis. BMC Cell Biol. 2004;5:5.

45. Tremblay GA, Richard S. mRNAs associated with the Sam68 RNA binding protein. RNA Biol. 2006;3(2):90-3.

46. Vogel G, Richard S. Emerging roles for Sam68 in adipogenesis and neuronal development. RNA Biol. 2012;9(9):1129-33.

47. Yang JP, Reddy TR, Truong KT, Suhasini M, Wong-Staal F. Functional interaction of Sam68 and heterogeneous nuclear ribonucleoprotein $\mathrm{K}$ Oncogene. 2002;21(47):7187-94.

48. Babic I, Jakymiw A, Fujita DJ. The RNA binding protein Sam68 is acetylated in tumor cell lines, and its acetylation correlates with enhanced RNA binding activity. Oncogene. 2004;23(21):3781-9.

49. Babic I, Cherry E, Fujita DJ. SUMO modification of Sam68 enhances its ability to repress cyclin D1 expression and inhibits its ability to induce apoptosis. Oncogene. 2006;25(36):4955-64.

50. Bedford MT, Frankel A, Yaffe MB, Clarke S, Leder P, Richard S. Arginine methylation inhibits the binding of proline-rich ligands to Src homology 3 , but not WW, domains. J Biol Chem. 2000;275(21):16030-6.
51. Cote J, Boisvert FM, Boulanger MC, Bedford MT, Richard S. Sam68 RNA binding protein is an in vivo substrate for protein arginine $\mathrm{N}$-methyltransferase 1. Mol Biol Cell. 2003;14(1):274-87.

52. Derry JJ, Richard S, Valderrama Carvajal H, Ye X, Vasioukhin V, Cochrane AW, et al. Sik (BRK) phosphorylates Sam68 in the nucleus and negatively regulates its RNA binding ability. Mol Cell Biol. 2000;20(16):6114-26

53. Sette C. Post-translational regulation of star proteins and effects on their biological functions. Adv Exp Med Biol. 2010;693:54-66.

54. Sharma R, Raychaudhuri S, Dasgupta A. Nuclear entry of poliovirus protease-polymerase precursor 3CD: implications for host cell transcription shut-off. Virology. 2004;320(2):195-205.

55. LaRocco M, Krug PW, Kramer E, Ahmed Z, Pacheco JM, Duque H, et al. A continuous bovine kidney cell line constitutively expressing bovine alphavbeta6 integrin has increased susceptibility to foot-and-mouth disease virus. J Clin Microbiol. 2013;51(6):1714-20.

56. Swaney LM. A continuous bovine kidney cell line for routine assays of foot-and-mouth disease virus. Vet Microbiol. 1988;18(1):1-14.

57. De Castro MP. Behaviour of the foot-and-mouth disease virus in cell cultures: Susceptibility of the IB-RS-2 line. Arch Inst Biol, Sao Paulo. 1964:31:63-78.

58. Borghese F, Michiels T. The leader protein of cardioviruses inhibits stress granule assembly. J Virol. 2011;85(18):9614-22.

59. Finnen RL, Pangka KR, Banfield BW. Herpes simplex virus 2 infection impacts stress granule accumulation. J Virol. 2012;86(15):8119-30.

60. Henao-Mejia J, He JJ. Sam68 relocalization into stress granules in response to oxidative stress through complexing with TIA-1. Exp Cell Res. 2009;315(19):3381-95.

61. Henao-Mejia J, Liu Y, Park IW, Zhang J, Sanford J, He JJ. Suppression of HIV-1 Nef translation by Sam68 mutant-induced stress granules and nef mRNA sequestration. Mol Cell. 2009;33(1):87-96.

62. Martinez-Salas E, Lozano G, Fernandez-Chamorro J, Francisco-Velilla R, Galan A, Diaz R. RNA-binding proteins impacting on internal initiation of translation. Int J Mol Sci. 2013;14(11):21705-26.

63. Serrano P, Ramajo J, Martinez-Salas E. Rescue of internal initiation of translation by RNA complementation provides evidence for a distribution of functions between individual IRES domains. Virology. 2009;388(1):221-9.

64. Ramos R, Martinez-Salas E. Long-range RNA interactions between structural domains of the aphthovirus internal ribosome entry site (IRES). RNA. 1999:5(10):1374-83.

65. Jackson RJ, Hellen CU, Pestova TV. The mechanism of eukaryotic translation initiation and principles of its regulation. Nat Rev Mol Cell Biol. 2010;11(2):113-27.

66. Yu Y, Sweeney TR, Kafasla P, Jackson RJ, Pestova TV, Hellen CU. The mechanism of translation initiation on Aichivirus RNA mediated by a novel type of picornavirus IRES. EMBO J. 2011;30(21):4423-36.

67. Fernandez N, Buddrus L, Pineiro D, Martinez-Salas E. Evolutionary conserved motifs constrain the RNA structure organization of picornavirus IRES. FEBS Lett. 2013:587(9):1353-8.

68. Fernandez N, Garcia-Sacristan A, Ramajo J, Briones C, Martinez-Salas E. Structural analysis provides insights into the modular organization of picornavirus IRES. Virology. 2011;409(2):251-61.

69. Chen T, Damaj BB, Herrera C, Lasko P, Richard S. Self-association of the single-KH-domain family members Sam68, GRP33, GLD-1, and Qk1: role of the KH domain. Mol Cell Biol. 1997;17(10):5707-18.

70. Di Fruscio $M$, Chen T, Richard S. Characterization of Sam68-like mammalian proteins SLM-1 and SLM-2: SLM-1 is a Src substrate during mitosis. Proc Nat Acad Sci U S A. 1999;96(6):2710-5.

71. Galarneau A, Richard S. The STAR RNA binding proteins GLD-1, QKI, SAM68 and SLM-2 bind bipartite RNA motifs. BMC Mol Biol. 2009;10:47.

72. Meyer NH, Tripsianes K, Vincendeau M, Madl T, Kateb F, Brack-Werner R, et al. Structural basis for homodimerization of the Src-associated during mitosis, 68-kDa protein (Sam68) Qua1 domain. J Biol Chem. 2010:285(37):28893-901.

73. Di Fruscio M, Chen T, Bonyadi S, Lasko P, Richard S. The identification of two Drosophila K homology domain proteins. Kep1 and SAM are members of the Sam68 family of GSG domain proteins. J Biol Chem. 1998:273(46):30122-30.

74. Murphy SM, Bergman M, Morgan DO. Suppression of C-Src activity by C-terminal Src kinase involves the c-Src SH2 and SH3 domains: analysis with Saccharomyces cerevisiae. Mol Cell Biol. 1993;13(9):5290-300. 
75. Lin JY, Chen TC, Weng KF, Chang SC, Chen LL, Shih SR. Viral and host proteins involved in picornavirus life cycle. J Biomed Sci. 2009;16:103.

76. Gustin KE, Sarnow P. Inhibition of nuclear import and alteration of nuclear pore complex composition by rhinovirus. J Virol. 2002;76(17):8787-96.

77. Zhang $H$, Song $L$, Cong $H$, Tien $P$. The nuclear protein Sam68 interacts with Enterovirus 71 internal ribosome entry site and positively regulates viral protein translation. J Virol. 2015;89:10031-43.

78. Zhang $\mathrm{H}$, Cong $\mathrm{H}$, Song $\mathrm{L}$, Tien $\mathrm{P}$. The nuclear protein Sam68 is redistributed to the cytoplasm and is involved in PI3K/Akt activation during EV71 infection. Virus Res. 2014;180:1-11.

79. Walsh D, Mohr I. Viral subversion of the host protein synthesis machinery. Nat Rev Microbiol. 2011;9(12):860-75.

80. Pacheco A, Reigadas S, Martinez-Salas E. Riboproteomic analysis of polypeptides interacting with the internal ribosome-entry site element of foot-and-mouth disease viral RNA. Proteomics. 2008;8(22):4782-90.

81. Lopez de Quinto S, Lafuente E, Martinez-Salas E. IRES interaction with translation initiation factors: functional characterization of novel RNA contacts with elF3, elF4B, and elF4GII. RNA. 2001;7(9):1213-26.

82. Rust RC, Ochs K, Meyer K, Beck E, Niepmann M. Interaction of eukaryotic initiation factor elF4B with the internal ribosome entry site of foot-and-mouth disease virus is independent of the polypyrimidine tract-binding protein. J Virol. 1999;73(7):6111-3.

83. Serrano P, Gomez J, Martinez-Salas E. Characterization of a cyanobacterial RNase $P$ ribozyme recognition motif in the IRES of foot-and-mouth disease virus reveals a unique structural element. RNA. 2007;13(6):849-59.

84. Serrano P, Pulido MR, Saiz M, Martinez-Salas E. The 3' end of the foot-andmouth disease virus genome establishes two distinct long-range RNA-RNA interactions with the 5' end region. J Gen Virol. 2006;87(Pt 10):3013-22.

85. Valverde R, Edwards L, Regan L. Structure and function of $K H$ domains. FEBS J. 2008;275(11):2712-26.

86. Itoh M, Haga I, Li QH, Fujisawa J. Identification of cellular mRNA targets for RNA-binding protein Sam68. Nucleic Acids Res. 2002;30(24):5452-64.

87. Pedrotti S, Bielli P, Paronetto MP, Ciccosanti F, Fimia GM, Stamm S, et al. The splicing regulator Sam68 binds to a novel exonic splicing silencer and functions in SMN2 alternative splicing in spinal muscular atrophy. EMBO J. 2010;29(7):1235-47.

88. Molla A, Paul AV, Wimmer E. Cell-free, de novo synthesis of poliovirus. Science. 1991;254(5038):1647-51.

89. Barton DJ, Flanegan JB. Synchronous replication of poliovirus RNA: initiation of negative-strand RNA synthesis requires the guanidine-inhibited activity of protein 2C. J Virol. 1997;71(11):8482-9.

90. Pogany J, Nagy PD. Authentic replication and recombination of Tomato bushy stunt virus RNA in a cell-free extract from yeast. J Virol. 2008;82(12):5967-80.

91. Franco D, Pathak HB, Cameron CE, Rombaut B, Wimmer E, Paul AV. Stimulation of poliovirus RNA synthesis and virus maturation in a HeLa cell-free in vitro translation-RNA replication system by viral protein 3CDpro. Virol J. 2005;2:86

92. Lopez de Quinto S, Martinez-Salas E. Parameters influencing translationa efficiency in aphthovirus IRES-based bicistronic expression vectors. Gene. 1998;217(1-2):51-6.

93. Ferrer-Orta C, de la Higuera I, Caridi F, Sanchez-Aparicio MT, Moreno E, Perales $C$, et al. Multifunctionality of a picornavirus polymerase domain: nuclear localization signal and nucleotide recognition. J Virol. 2015; 89(13):6848-59.

94. Garcia-Briones M, Rosas MF, Gonzalez-Magaldi M, Martin-Acebes MA, Sobrino F, Armas-Portela R. Differential distribution of non-structural proteins of foot-and-mouth disease virus in BHK-21 cells. Virology. 2006;349(2):409-21.

95. Sanchez-Aparicio MT, Rosas MF, Sobrino F. Characterization of a nuclear localization signal in the foot-and-mouth disease virus polymerase. Virology. 2013:444(1-2):203-10.

96. White JP, Cardenas AM, Marissen WE, Lloyd RE. Inhibition of cytoplasmic mRNA stress granule formation by a viral proteinase. Cell Host Microbe. 2007;2(5):295-305.

97. Rieder $\mathrm{E}$, Henry $\mathrm{T}$, Duque $\mathrm{H}, \mathrm{Baxt} \mathrm{B}$. Analysis of a foot-and-mouth disease virus type A24 isolate containing an SGD receptor recognition site in vitro and its pathogenesis in cattle. J Virol. 2005;79(20):12989-98.

98. Schneider R, Agol VI, Andino R, Bayard F, Cavener DR, Chappell SA, et al. New ways of initiating translation in eukaryotes. Mol Cell Biol. 2001; 21(23):8238-46.
99. Laemmli UK. Cleavage of structural proteins during the assembly of the head of bacteriophage T4. Nature. 1970;227(5259):680-5.

100. Kelley LA, Mezulis S, Yates CM, Wass MN, Sternberg MJ. The Phyre2 web portal for protein modeling, prediction and analysis. Nat Protoc. 2015;10(6):845-58.

101. Biasini M, Bienert S, Waterhouse A, Arnold K, Studer G, Schmidt T, et al. SWISS-MODEL: modelling protein tertiary and quaternary structure using evolutionary information. Nucleic Acids Res. 2014;42(Web Server issue):W252-8.

102. Kozakov D, Beglov D, Bohnuud T, Mottarella SE, Xia B, Hall DR, et al. How good is automated protein docking? Proteins. 2013;81(12):2159-66.

103. Cuconati A, Molla A, Wimmer E. Brefeldin A inhibits cell-free, de novo synthesis of poliovirus. J Virol. 1998;72(8):6456-64

\section{Submit your next manuscript to BioMed Central and we will help you at every step:}

- We accept pre-submission inquiries

- Our selector tool helps you to find the most relevant journal

- We provide round the clock customer support

- Convenient online submission

- Thorough peer review

- Inclusion in PubMed and all major indexing services

- Maximum visibility for your research

Submit your manuscript at www.biomedcentral.com/submit
Biomed Central 